\title{
Support System Effects on the NASA Common Research Model
}

\author{
Melissa B. Rivers* and Craig A. Hunter ${ }^{\dagger}$ \\ NASA Langley Research Center, Hampton, VA 23681
}

\begin{abstract}
An experimental investigation of the NASA Common Research Model was conducted in the NASA Langley National Transonic Facility and NASA Ames 11-Foot Transonic Wind Tunnel Facility for use in the Drag Prediction Workshop. As data from the experimental investigations was collected, a large difference in moment values was seen between the experimental and the computational data from the $4^{\text {th }}$ Drag Prediction Workshop. This difference led to the present work. In this study, a computational assessment has been undertaken to investigate model support system interference effects on the Common Research Model. The configurations computed during this investigation were the $\mathbf{w i n g} / \mathbf{b o d y} /$ tail $=0^{\circ}$ without the support system and the wing $/ \mathbf{b o d y} /$ tail $=0^{\circ}$ with the support system. The results from this investigation confirm that the addition of the support system to the computational cases does shift the pitching moment in the direction of the experimental results.
\end{abstract}

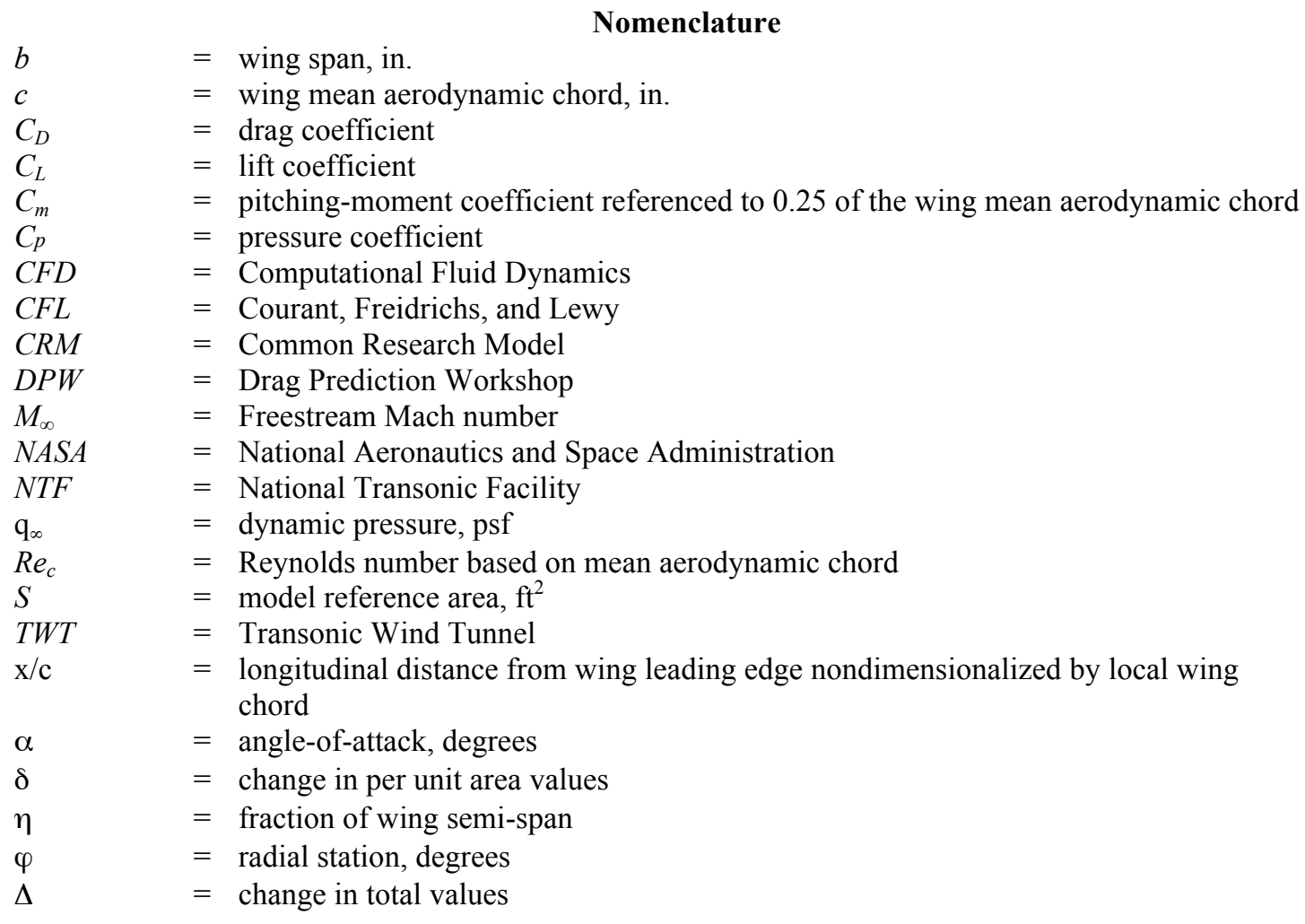

\section{Introduction}

Tn an effort to assess the state of the art in computational fluid dynamics (CFD) drag prediction, the AIAA 1 Applied Aerodynamics Technical Committee has initiated a series of Drag Prediction Workshops. The goal of the workshops is to assess state-of-the-art computational methods as practical aerodynamic tools for

\footnotetext{
* Research Engineer, Configuration Aerodynamics Branch, Mail Stop 267, Senior Member AIAA.

${ }^{\dagger}$ Research Engineer, Configuration Aerodynamics Branch, Mail Stop 499.
} 
aircraft force and moment prediction of industry relevant geometries, with a focus on drag prediction. Furthermore, the Drag Prediction Workshop (DPW) is designed to serve as an impartial forum for evaluating the effectiveness of existing computational Navier-Stokes solvers and modeling techniques, and is intended to promote an open discussion on areas needing additional research and development. In order to encourage the widest participation, public-domain subject geometries have been used that are industryrelevant, yet simple enough to permit high-fidelity computations. Additionally, baseline grids have been provided to reduce the variability of CFD results.

The first drag prediction workshop (DPW-I) ${ }^{1,2}$, held in June of 2001, was directed at the calculation of a wing/body commercial transport configuration, known as the DLR-F4 $4^{3,4}$. Previously obtained experimental data were available to compare to for this first workshop. Predictions of a cruise polar and drag rise were the focus. The second drag prediction workshop (DPW-II), ${ }^{5,6}$, held in June of 2003, added the challenge of determining the increment of a large component, in this case a pylon/nacelle. The DLR-F6 configuration ${ }^{5,7}$ was used for this study. Once again, experimental data were available for comparison. The third drag prediction workshop (DPW-III) ${ }^{8,9}$, held in June of 2006, added the challenge of determining the increment due to adding a small component, in this case a wing/body fairing. However for this workshop, calculations were conducted "blind" with no experimental data available prior to the workshop. Force and moment, surface pressure, model deformation, and surface flow visualization data were obtained in a National Transonic Facility (NTF) wind tunnel investigation on the DLR-F6 configuration in the fall of $2007^{10}$. The fourth drag prediction workshop (DPW-IV) ${ }^{11,12}$, held in June of 2009, was another set of blind calculations. However for this workshop, the calculations were conducted on a brand new model called the Common Research Model (CRM). It is these "blind" calculations that draw the connection between the fourth drag prediction workshop and the current experimental investigations. The force and moment, surface pressure, model deformation, and surface flow visualization data obtained in these two wind tunnel investigations, ${ }^{13}$ NASA Langley NTF and NASA Ames 11-Foot Transonic Wind Tunnel (TWT) Facility, on the CRM serve as the validation data for the calculations presented in the DPW-IV. The results presented in this paper, addressing model support system effects, serve as an addendum to the results obtained for the DPW-IV.

\section{Background}

\section{A. Facility Description}

\section{National Transonic Facility}

The $\mathrm{NTF}^{14}$ is a unique national facility (Figure 1) that enables testing of aircraft configurations at conditions ranging from subsonic to low supersonic speeds, at Reynolds numbers up to full-scale flight values. The NTF is a conventional, closed circuit, continuous-flow, fan-driven wind tunnel (Figure 2) capable of operating in either dry air at warm temperatures or nitrogen from warm to cryogenic temperatures. Elevated pressure in combination with cryogenic temperature enables testing to the highest Reynolds numbers. The test section is $8.2 \times 8.2 \times 25 \mathrm{ft}$ and has a slotted floor and ceiling. Turbulence is reduced by four damping screens in the settling chamber and a contraction ratio of 14.95:1 from the settling chamber to the nozzle throat. Fan-noise effects are minimized by acoustic treatment both upstream and downstream of the fan. Thermal insulation resides inside the pressure shell to aid in maintaining tunnel temperature and thus minimize energy consumption.

The NTF has an operating pressure range of approximately 15 to 125 psia, a temperature range of -260 to $+120^{\circ} \mathrm{F}$, and a Mach number range of 0.2 to 1.2 . The maximum Reynolds number per foot is $146 \times 10^{6}$ at Mach 1. When the tunnel is operated cryogenically, heat is removed by the evaporation of liquid nitrogen, which is sprayed into the tunnel circuit upstream of the fan. During this operational mode, venting is necessary to maintain a constant total pressure. When air is the test gas, heat is removed from the system by a water-cooled heat exchanger at the upstream end of the settling chamber. Further tunnel details and facility information are provided in Reference 15.

\section{Ames 11-Foot Transonic Wind Tunnel Facility}

The Unitary Plan Wind Tunnel (UPWT) Facility consists of three tunnel legs: the 11-by-11-Foot TWT, the 9-by-7-Foot Supersonic Wind Tunnel, and the 8-by-7-Foot Supersonic Wind Tunnel (Figure 3). The two supersonic legs share a common 11-stage axial-flow compressor and aftercooler drive leg, and they use diversion valves at the ends of a common drive leg. A three-stage axial-flow compressor drives the 11-by- 
11-Foot TWT. A common drive motor system can be coupled to either the 3-stage or 11-stage compressor. One tunnel can therefore be run while test articles are being installed in or removed from the other two.

The 11-by-11-Foot TWT leg, also known as the Ames 11-ft wind tunnel, is a closed-circuit, variablepressure, continuous operation wind tunnel (Figure 4). Subsonic Mach number control involves setting the compressor drive speed to one of ten setpoints and using variable-camber inlet guide vanes for fine Mach number control. Supersonic Mach number control involves setting the flexible wall nozzle to achieve the proper area ratio in addition to setting the compressor drive speed and the inlet guide vanes. A tandem diffuser system with an annular diffuser followed by a wide-angle diffuser is upstream of a 70-ft-diameter aftercooler section in the drive leg. Flow-smoothing vanes are located in the tandem diffuser to improve flow uniformity entering the heat exchanger and temperature uniformity in the test section. The settling chamber upstream of the contraction is 38 feet in diameter. A Turbulence Reduction System (TRS) located in the settling chamber includes a 1-in.-cell-diameter, 20-in. long honeycomb for flow straightening followed by two 0.041-in.-diameter-wire, 6-mesh screens for turbulence reduction. The contraction provides a transition from the circular cross section of the settling chamber to the square cross section of the test section. The contraction ratio is 9.4:1. The test section is 11-by-11-feet in cross-section and 22 feet in length. Slots in all four walls run the full length of the test section. The slots contain baffles that provide a 6-percent porosity into the plenum chamber. Ejector flaps on all four walls at the exit of the test section can be set remotely to control the plenum flow bypassed from the test section. Flow exits the test section and enters a transition region back to the circular main diffuser. A Plenum Evacuation System (PES) provides an active method of removing air from the test section plenum by using the Make-Up Air compressor system (MUA) of the auxiliaries facility. References 16 and 17 provide more detailed information about the Ames 11-Foot Transonic Wind Tunnel Facility.

\section{B. Model Description}

The model used in the current investigation was the NASA Common Research Model (CRM). This configuration consists of a contemporary supercritical transonic wing and a fuselage that is representative of a wide-body commercial transport aircraft. The CRM is designed for a cruise Mach number of 0.85 and a corresponding design lift coefficient of $\mathrm{C}_{\mathrm{L}}=0.5$. A sketch of the CRM with the reference quantities listed is shown in Figure 5. The aspect ratio is 9.0, the leading edge sweep angle is $35^{\circ}$, the wing reference area (S) is $3.01 \mathrm{ft}^{2}$, the wing span (b) is 62.47 inches, and the mean aerodynamic chord (c) is 7.45 inches. The model moment reference center is located 35.8 inches back from the fuselage nose and 2.04 inches below the fuselage centerline. The nacelles used for this test were simple, flow through nacelles. Pressure distributions are measured on both the left and right wings using 291 pressure orifices located in 9 spanwise wing stations $(\eta=0.131,0.201,0.283,0.397,0.502,0.603,0.727,0.846$, and 0.950$)$ and on the left nacelle by 6 orifices at 6 radial stations $\left(\varphi=30^{\circ}, 90^{\circ}, 150^{\circ}, 210^{\circ}, 270^{\circ}\right.$, and $\left.330^{\circ}\right)$. All pressure measurements were made using Electronically Scanned Pressure (ESP) modules mounted inside the forward portion of the fuselage. Based on quoted accuracies from the ESP module manufacturer, surface pressure measurements should be in error no more than $+/-0.015$ psi. This in turn would correspond to a variation of no more than $+/-0.0026$ in terms of $\mathrm{Cp}$. The model is mounted in the wind tunnel using a blade sting arrangement as shown in Figure 6 and Figure 7.

Five different configurations were tested in the experimental investigations: the wing/body alone, wing $/$ body $/$ pylon/nacelle, wing $/$ body $/$ tail $=0^{\circ}$, wing $/$ body $/$ tail $=+2^{\circ}$ and wing $/$ body $/$ tail $=-2^{\circ}$. For the current study, though, the focus is on the wing/body $/$ tail $=0^{\circ}$ configuration. In the rest of the paper the wing $/$ body/tail $=0^{\circ}$ will be mentioned as the without support system configuration. Further details on this geometry are given in Ref. 18.

\section{Test Conditions}

\section{National Transonic Facility}

The investigation, conducted over a 6-week period, provided force and moment, surface pressure, model deformation, and surface flow visualization data. Testing was conducted at 5, 19.8 and 30 million Reynolds number. All Reynolds number values presented in this paper are based on mean aerodynamic chord. The 5 and 19.8 million Reynolds number data were collected to provide a comparison to previously calculated CFD results and all of the Reynolds numbers were used to provide an assessment of Reynolds number effects. The 19.8 million Reynolds number data were collected at two different $\mathrm{q}_{\infty}$ levels $-\mathrm{a}$ high and a low $\mathrm{q}_{\infty}$ condition. Having two $\mathrm{q}_{\infty}$ levels at the same Reynolds number provides an aeroelastic step in 
the data. The data were collected at temperatures ranging from $-250^{\circ} \mathrm{F}$ up to $120^{\circ} \mathrm{F}$. For the comparisons made in this paper, only the $\operatorname{Re}_{\mathrm{c}}=5$ million data obtained at a temperature of $120^{\circ} \mathrm{F}$ are presented.

All data presented in this paper were obtained at freestream Mach number of 0.85 . Data were generally obtained over an angle-of-attack range from $-3^{\circ}$ to $+12^{\circ}$ at 5 million Reynolds number and from $-3^{\circ}$ to $+6^{\circ}$ at 19.8 and 30 million Reynolds numbers. The reduced angle-of-attack range at the higher Reynolds number was required such that safe model stress levels would not be exceeded. Flow angularity measurements were made and upflow corrections ranging from $0.092^{\circ}$ to $0.173^{\circ}$ were applied to the final NTF data. Classical wall corrections accounting for model blockage, wake blockage, tunnel buoyancy, and lift interference have been applied according to the methods presented below.

In order to ensure a consistent and repeatable transition from laminar to turbulent flow and to support the goal of the wind tunnel data being used for CFD validation purposes, it was important to apply a proven and reliable method to fix transition on the model. Evercoat trip dots measuring 0.05 inches in diameter and spaced 0.1 inches apart (center to center) were used for the current investigation. For a chord Reynolds number of 5 million, a trip dot height of 0.0035 inches was used from the SOB (side of body) to the yehudi break, 0.003 inches was used from the yehudi break to the midwing and 0.003 inches was used from the midwing to the wing tip. These trip dots were installed at $10 \%$ chord. Vinyl adhesive trip dots with a height of 0.004 inches were applied at the nose of the fuselage and left on for the entire test. When the nacelles were on the model, trip dots with a height of 0.003 inches were located 0.43 inches back from the leading edge on the outer surface and the inner surface. Finally, when the tails were on the model, trip dots were located at $10 \%$ chord and measured 0.003 inches in height. Further information about this investigation can be found in reference 19 .

\section{Ames 11-ft Wind Tunnel}

The investigation, conducted over a 5-week period, provided force and moment, surface pressure, and surface flow visualization data. Testing was conducted at a chord Reynolds number of 5 million. The data were collected at temperatures of approximately $100^{\circ} \mathrm{F}$.

All data presented in this paper were obtained at a freestream Mach numbers of 0.85. Data were generally obtained over an angle-of-attack range from $-3^{\circ}$ to $+12^{\circ}$ at 5 million chord Reynolds number. Flow angularity measurements were made and upflow corrections ranging from $0.013^{\circ}$ to $0.067^{\circ}$ were applied to the final data. Classical wall corrections accounting for tunnel buoyancy and lift interference have been applied according to the method presented below.

Transition was also fixed on the model when tested at the Ames 11-ft wind tunnel. For this investigation, though, only vinyl adhesive trip dots were applied. These trip dots measured 0.05 inches in diameter and were spaced 0.1 inches apart. For a chord Reynolds number of 5 million, a trip dot height of 0.0035 inches was used from the SOB (side of body) to the yehudi break, 0.003 inches was used from the yehudi break to the midwing and 0.003 inches was used from the midwing to the wing tip. These trip dots were installed at $10 \%$ chord. Vinyl adhesive trip dots with a height of 0.004 inches were also applied at the nose of the fuselage and left on for the entire test. When the nacelles were on the model, trip dots with a height of 0.003 inches were located 0.43 inches back from the leading edge on the outer surface and the inner surface. Finally, when the tails were on the model, trip dots were located at $10 \%$ chord and measured 0.003 inches in height.

\section{Wall Correction Methods for NTF and Ames 11-ft Wind Tunnels}

Both the NTF and the Ames 11-ft wind tunnels use the Transonic Wall Interference Correction System (TWICS) to provide blockage and incidence corrections due to the presence of the test section boundary. TWICS and its predecessor, the Wall Interference Correction System (WICS), were developed at the NASA Ames Research Center by Ulbrich et al. ${ }^{20-27}$ as a modification and extension of the Hackett wall signature method. ${ }^{28-32}$ TWICS is an enhanced version of WICS that handles ventilated boundary conditions, typically seen in transonic wind tunnels. This method was chosen to be implemented at the NTF, see Iyer et al., ${ }^{33,34}$ in an effort to standardize the wall interference correction methodology across NASA centers. TWICS is based on a linearized potential flow method with a Prandtl-Glauert compressibility model which inherently assumes that there is a portion of flow in the test section between the near-field region of the test article and the near-field region of the wall that is a linear perturbation of the empty test section flow field.

The method uses a tared wall pressure signature, which is the difference between the model installed condition and the empty test section, a database of normalized perturbation velocities using unit singularity solutions computed for a given mathematical representation of the wall boundary condition, and geometric 
information from the test article. Taring of the wall pressure signature is performed to remove first order effects of the empty tunnel boundary layer and buoyancy, assumed to contain only the solid and wake blockage, and assumed that the additional second order change in the test-section-wall boundary layer displacement thickness due to the presence of the test article is negligible - an assumption that is violated by flow near a Mach number of unity where aspects of the crossflow are more critical. The test article is modeled with an appropriately weighted point doublet chain ${ }^{35}$ to represent the fuselage, wake, and support system. Line doublets, typically distributed along the lifting surface quarter-chord, are used to simulate the effect of lift. The strengths of the line doublets are determined using the measured lift from the balance. The resulting wall signature from these singularities is subtracted from the tared wall signature, leaving only the blockage signature. This remaining signature is used to determine the strengths of the solid and wake blockage singularities.

Although both facilities use TWICS, the implementations are not identical. The differences occur in how the wall boundary conditions are formulated and applied. Ulbrich ${ }^{26,27}$ performed a calibration and validation of the baffled, slotted (i.e. porous) wall boundary condition for the Ames 11-ft wind tunnel. Walker ${ }^{36}$ calibrated and validated the longitudinal slotted wall boundary condition in the NTF. A discrete wall formulation, where the boundary condition is applied in the baffled slot, is used at the Ames 11-ft wind tunnel; whereas, a homogeneous wall formulation, which is more of an averaged representation of the effect of the ventilated wall boundary, is used at the NTF. Work is in progress to assess the impact of modeling the NTF wall boundary condition as discrete. It is anticipated that a change to the discrete formulation of the NTF may lead to a decreased incidence correction. Data presented in this paper are corrected using the respective implementations of TWICS at each facility.

\section{E. Comparison of Wind Tunnel and Computational Data}

While comparing the data obtained in the two wind tunnels with the computational data obtained from the DPW IV, an unusually large discrepancy in pitching moment was noted, while the lift and drag comparisons were as expected (Figure 8). One approach to explaining this discrepancy was to determine what effects the support system had on the model while mounted in the tunnel. This approach is what is presented herein.

\section{Computational Approach}

\section{A. Grid Generation}

The GridTool/VGRID software system ${ }^{37}$ was used to generate unstructured grids for this study. VGRID uses an advancing-front method for generating Euler tetrahedral grids, and an advancing-layer method for thin-layer tetrahedral viscous grids required for Navier-Stokes analysis. In defining the computational domain, boundaries are represented by bi-linear surface patches that are constructed in GridTool based on user-specified geometries and an IGES definition. Grid characteristics like cell spacing and stretching are also specified in GridTool by the placement of volume, node, and linear sources.

A surface mesh is generated in VGRID by triangulating each surface patch with a two-dimensional version of the advancing-front method. Triangulated surface patches then form the initial front for the generation of three-dimensional tetrahedral volume cells by the advancing-layer and advancing-front methods. Smooth variation of grid spacing is achieved with an exponential growth function, using the GridTool-defined sources as inputs.

Two semi-span grids were developed for this study: a grid containing the wing $/$ body $/$ tail $=0^{\circ}$ without the support system and a grid containing the wing $/$ body $/$ tail $=0^{\circ}$ with the support system. Surface meshes from both grids are shown in Figure 9 and Figure 10. Grid sizes ranged from 22.6 million cells for the wing $/$ body $/$ tail $=0^{\circ}$ without support system to 27.3 million cells for the wing $/$ body/tail $=0^{\circ}$ with support system. Boundary layers were resolved using approximately 96 tetrahedral cells (32 nodes), with first cell centroid at $\mathrm{y}^{+}$of 0.25 . In all cases, the computational domain extended roughly 10 body lengths from the aircraft fuselage in all directions.

\section{B. Flow Solver}

The NASA Langley unstructured computational fluid dynamics code USM3D $6.0^{38-41}$ was used for Navier-Stokes analysis in this study. Within the tetrahedral cell-centered, finite volume flow solver, inviscid flux quantities are computed across each cell face using one of the following schemes: Roe's fluxdifference splitting (FDS), Advection Upstream Splitting Method (AUSM), Flux Vector Splitting (FVS), or 
Harten, Lax, and van Leer with Contact restoration (HLLC). A novel reconstruction process is used for spatial discretization, based on an analytical formulation for computing gradients within tetrahedral cells. Solutions are advanced to a steady state condition using an implicit backward-Euler time-stepping scheme. For numerical stability, limiter options include MinMod and Superbee flux limiters and an Eigen-value limiter. Turbulence closure in USM3D 6.0 is given by the one equation Spalart-Allmaras (SA) model, the two-equation k- $\varepsilon$ turbulence model, or the two-equation Menter SST model. For the present study, FDS and Spalart-Allmaras were used. To improve the prediction of skin friction drag, a solution limiter was not activated.

\section{Boundary Conditions}

Outer boundaries of the computational domain were treated as characteristic inflow/outflow surfaces with freestream conditions specified by Mach number, Reynolds number, flow angle, and static temperature. For comparison with wind tunnel data, a freestream Mach number of 0.85 and a Reynolds number of 5 million based on mean aerodynamic chord were chosen. Solutions were run over a range of angles-of-attack from $0^{\circ}$ to $5^{\circ}$.

A reflection boundary condition was used at the symmetry plane of the semi-span geometry. All other aircraft and model support system surfaces were treated as no-slip viscous boundaries.

\section{Solution Procedure}

Solutions presented in this paper were obtained by running USM3D on the k cluster at NASA Langley Research Center using 48 processors. Cases typically needed 20,000 cycles for full convergence, requiring 13 to 30 hours of wall-clock time. During the computation, global CFL number ramped from 1 to 50 . Convergence was judged by tracking the solution residual and integrated aerodynamic performance coefficients until they settled out in a satisfactory fashion. A typical convergence history is shown in Figure 11.

\section{E. Force and Moment Integration}

Forces and moments were computed within the flow solver by evaluating pressure and skin friction on the surface. Force and moment coefficients given in this paper were computed for the aircraft (wing/body $/$ tail $=0^{\circ}$ ) by itself. Forces and moments on the support system components were ignored. Because the contribution of forces in the small area where the blade intersected the aircraft fuselage were small, no attempt was made to reconcile or correct these forces when comparing configurations with and without the support system.

\section{Results and Discussion}

This study consisted of computing cases at a Mach number of 0.85 and a Reynolds number of 5 million based on mean aerodynamic chord. The solutions were run over a range of angles-of-attack from $0^{\circ}$ to $5^{\circ}$. Summary results from the $\alpha=0.0^{\circ}, 2.5^{\circ}$, and $5.0^{\circ}$ cases are shown in Table 1 below, where the delta coefficients are relative to the without support system cases:

Table 1: Summary of CFD Cases, $M_{\infty}=0.85, \operatorname{Re}_{\mathrm{c}}=5 \times 10^{6}$

\begin{tabular}{|l|c|c|c|c|c|c|c|}
\hline CFD Case & $\boldsymbol{\alpha}$ & $\mathbf{C}_{\mathbf{m}}$ & $\mathbf{C}_{\mathbf{L}}$ & $\mathbf{C}_{\mathbf{D}}$ & $\boldsymbol{\Delta} \mathbf{C}_{\mathbf{m}}$ & $\Delta \mathbf{C}_{\mathbf{L}}$ & $\Delta \mathbf{C}_{\mathbf{D}}$ \\
\hline Without Support System & 0.0 & 0.0548 & 0.1778 & 0.01874 & & & \\
\hline With Support System & 0.0 & 0.0962 & 0.1572 & 0.01612 & 0.0414 & -0.0206 & -0.00262 \\
\hline Without Support System & 2.5 & -0.0625 & 0.5424 & 0.02995 & & & \\
\hline With Support System & 2.5 & -0.0158 & 0.5151 & 0.01252 & 0.0467 & -0.0273 & -0.00417 \\
\hline Without Support System & 5.0 & -0.0632 & 0.7311 & 0.06842 & & & \\
\hline With Support System & 5.0 & -0.0181 & 0.7183 & 0.06248 & 0.0450 & -0.0128 & -0.00594 \\
\hline
\end{tabular}

After all of the CFD cases were completed, the data were plotted against the NTF, Ames TWT and DPW IV data to determine what effect the support system had on the lift, drag and pitching moment. This plot is shown in Figure 12. The plot results confirm that including the support system in the computational analyses does shift the pitching moment in the direction of the experimental results. The lift is decreased a 
small amount and the drag is also decreased, from 26 counts at $\alpha=0^{\circ}$ up to 60 counts at $\alpha=5^{\circ}$. To further investigate these differences, pressure coefficient $\left(\mathrm{C}_{\mathrm{P}}\right)$ contours were examined.

Figure 13 thru Figure 18 show surface pressure coefficient contours for both configurations. The angleof-attack variations will be discussed separately below. In general, though, these figures show that adding the support system does change the surface pressures for each of the three angles-of-attack shown.

To better understand variations in surface pressure, the change in pressure coefficient $\left(\Delta \mathrm{C}_{\mathrm{P}}\right)$ is also examined. This is obtained by subtracting the without support system configuration's surface pressure coefficient from the with support system configuration's surface pressure coefficient. This can be studied in even more detail by breaking $\Delta \mathrm{C}_{\mathrm{P}}$ out into its lift, drag, and pitch contributions. Lift and drag quantities are obtained by multiplying $\Delta \mathrm{C}_{\mathrm{P}}$ by a dot product between the local surface unit normal vector and a unit vector in the lift- and drag-directions, respectively. Pitch quantities are obtained by multiplying $\Delta \mathrm{C}_{\mathrm{P}}$ by a cross product between the local surface unit normal vector and the normalized (by reference chord) lever arm to the pitch axis at the aircraft moment center. This results in plots of lift, drag, and pitch coefficient per-unit-area (i.e., the integrands in traditional pressure-based lift, drag, and pitch integrations), but it is equally effective to think of these quantities as the influence of $\Delta \mathrm{C}_{\mathrm{P}}$ in the respective force directions and moment rotations. These per-unit-area values are denoted with a $\delta$ in the results shown below.

\section{A. Angle-of-Attack $=0^{\circ}$ Case}

Figure 19 presents $\Delta C_{P}$ for the full support system configuration at $\alpha=0^{\circ}$. This figure shows a significant change in loads in the aft fuselage region (where the support system attaches to the fuselage).

The $\delta \mathrm{C}_{\mathrm{m}}$ for the support system configuration at $\alpha=0^{\circ}$ is shown in Figure 20. This figure shows that there is a significant change in the pitching moment on the upper surface aft fuselage and horizontal tail and on the lower surface horizontal tail. Figure 21 shows $\delta C_{L}$ for the support system configuration at $\alpha=0^{\circ}$ and Figure 22 shows $\delta C_{D}$. Here the effects of the support system are also apparent - it results in significant local lift per-unit-area changes (both positive and negative) in the aft fuselage and horizontal tail area. The biggest per-unit-area change in drag occurs in the area where the support system attaches to the fuselage and on the horizontal tail.

In terms of net force coefficients, the support system configuration at $\alpha=0^{\circ}$ had an increase in pitching moment of $\Delta \mathrm{C}_{\mathrm{m}}=0.0414$, a reduction in lift coefficient of $\Delta \mathrm{C}_{\mathrm{L}}=-0.0206$ and a reduction in drag coefficient of $\Delta \mathrm{C}_{\mathrm{D}}=-0.00262$ relative to the without support system case.

\section{B. Angle-of-Attack $=2.5^{\circ}$ Case}

Figure 23 shows $\Delta \mathrm{C}_{\mathrm{P}}$ for the support system configuration at $\alpha=2.5^{\circ}$. This figures shows a significant change in shock loading across the upper surface wing and a significant change in loads in the aft fuselage region. The $\delta \mathrm{C}_{\mathrm{m}}$ plot is shown in Figure 24. The pitching moment increases toward the tip of the upper wing surface and shows significant changes in pitching moment on the upper surface aft fuselage and the horizontal tail. The $\delta C_{L}$ plot shown in Figure 25 shows a significant local lift per-unit-area change in the aft fuselage and horizontal tail area and in the wing upper surface shock region. In Figure 26, the $\delta C_{D}$ shows a reduction in drag on the upper surface of the wing and a large per-unit-area change occurring in the area where the support system attaches to the fuselage and on the horizontal tail. This analysis case is near the cruise design point for the $\mathrm{CRM}$, at $\mathrm{M}_{\infty}=0.85$ and $\mathrm{C}_{\mathrm{L}}=0.5$, with a weak shock on the upper surface of the wing. However, the sensitivity to the support system can be seen by its influence of stronger shock loading along the upper surface of the wing.

In terms of net force coefficients, the support system configuration at $\alpha=2.5^{\circ}$ showed an increase of pitching moment of $\Delta \mathrm{C}_{\mathrm{m}}=0.0467$, a reduction in lift coefficient of $\Delta \mathrm{C}_{\mathrm{L}}=-0.0273$ and a reduction in drag coefficient of $\Delta \mathrm{C}_{\mathrm{D}}=-0.00417$ relative to the without support system case.

\section{Angle-of-Attack $=5^{\circ}$ Case}

Figure 27 shows $\Delta \mathrm{C}_{\mathrm{P}}$ for the support system configuration at $\alpha=5^{\circ}$. This figures shows a minor change in shock loading across the upper wing surface and a significant change in loads in the aft fuselage region. The $\delta C_{m}$ plot is shown in Figure 28. The pitching moment shows significant changes on the upper surface aft fuselage and the horizontal tail. $\delta C_{L}$ and $\delta C_{D}$ plots are shown in Figure 29 and Figure 30, respectively. Once again the addition of the support system results in significant local lift per-unit-area changes in the upper wing surface, aft fuselage and horizontal tail areas. There is also a small decrease in drag on the 
inboard wing upper surface and a large per-unit-area change in the aft fuselage region. There is also an increase in drag on the leading edge of the horizontal tail.

In terms of net force coefficients, the support system configuration at $\alpha=5^{\circ}$ showed an increase of pitching moment of $\Delta \mathrm{C}_{\mathrm{m}}=0.045$, a reduction in lift coefficient of $\Delta \mathrm{C}_{\mathrm{L}}=-0.0128$ and a reduction in drag coefficient of $\Delta \mathrm{C}_{\mathrm{D}}=-0.00594$ relative to the wing/body/tail $=0^{\circ}$ alone case.

\section{Conclusion}

A computational assessment has been conducted in an effort to investigate model support system interference effects on the NASA Common Research Model. The configurations computed during this investigation were the wing/body $/$ tail $=0^{\circ}$ without support system and the wing $/$ body $/$ tail $=0^{\circ}$ with support system at angles-of-attack of $0^{\circ}, 2.5^{\circ}$ and $5^{\circ}$. The configurations were compared at a Mach number of 0.85 and Reynolds number of 5 million based on mean aerodynamic chord.

Several important points arise from the results discussed in this paper. First and foremost, these results suggest that the model support system for the CRM configuration tested in the NTF and the Ames 11-ft wind tunnels indeed effects measured aerodynamic performance. While a more rigorous computational study is needed to further classify support system effects over a wider range of flow conditions, the current results indicate the need to either develop support system corrections for NTF and Ames 11- $\mathrm{ft}$ data or include the support system in computational studies attempting to predict the CRM configuration. The corrections or predictions need to at least include the support system.

The biggest result from this investigation is the confirmation that the addition of the support system to the computational cases does shift the pitching moment in the direction of the experimental results. A follow on investigation will look at the arc sector and wind tunnel wall effects in the computational analyses to better understand their influence on the results. 


\section{References}

${ }^{1}$ Levy, D. W., Vassberg, J. C., Wahls, R. A., Zickhur, T., Agrawal, S., Pirzadeh, S., and Hemsch, M. J., "Summary of Data from the First AIAA CFD Drag Prediction Workshop," AIAA Paper 2002-0841, January 2002.

${ }^{2}$ Hemsch, M. J., "Statistical Analysis of CFD Solutions from the Drag Prediction Workshop," AIAA Paper 20020842, January 2002.

${ }^{3}$ Redeker, G., Schmidt, N., and Müller, R., "Design and Experimental Verification of a Transonic Wing for a Transport Aircraft," Proceedings of the FDP Symposium on Subsonic/Transonic Configuration Aerodynamics, AGARD CP 285, 1980, pp. 13.1-13.7.

${ }^{4}$ Redeker, G., "DLR-F4 Wing Body Configuration," A Selection of Experimental Test Cases for the Validation of CFD Codes, AGARD Report AR-303, Vol. 2, 1994, pp. B4-1-21.

${ }^{5}$ Laflin, K. R., Vassberg, J. C., Wahls, R. A., Morrison, J. H., Brodersen, O., Radowitz, M., Tinoco, E. N., and Godard, J., "Summary of Data from the Second AIAA CFD Drag Prediction Workshop," AIAA Paper 2004-0555, January 2004.

${ }^{6}$ Hemsch, M. J. and Morrison, J. H., "Statistical Analysis of CFD Solutions from the 2nd Drag Prediction Workshop,” AIAA Paper 2004-0556, January 2004.

${ }^{7}$ Rossow, C.-C., Godard, J.-L., Hoheisel, H., and Schmitt, V., "Investigations of Propulsion Integration Interference Effects on a Transport Aircraft Configuration," Journal of Aircraft, Vol. 31, No. 5, 1994, pp. 1022-1030.

${ }^{8}$ Vassberg, J. C., Tinoco, E. N., Mani, M., Broderson, O. P., Eisfeld, B., Wahls, R. A., Morrison, J. H., Zickuhr, T., Laflin, K. R., and Mavriplis, D. J., "Summary of the Third AIAA CFD Drag Prediction Workshop," AIAA Paper 20070260, January 2007.

${ }^{9}$ Morrison, J. H. and Hemsch, M. J., "Statistical Analysis of CFD Solutions from the Third AIAA Drag Prediction Workshop," AIAA Paper 2007-0254, January 2007.

${ }^{10}$ Gatlin, G. M., Rivers, M. B., Goodliff, S. L., Rudnik, R., and Sitzmann, M., "Experimental Investigation of the DLR-F6 Transport Configuration in the National Transonic Facility," AIAA Paper 2008-6917, August 2008.

${ }^{11}$ Vassberg, J. C., Tinoco, E. N., Mani, M., Rider, B., Zickuhr, T., Levy, D.W., Brodersen, O., Eisfeld, B., Crippa, S., Wahls, R. A., Morrison, J. H., Mavriplis, D.J., and Murayama, M., "Summary of the Fourth AIAA CFD Drag Prediction Workshop," AIAA Paper 2010-4547, June 2010.

${ }^{12}$ Morrison, J. H., "Statistical Analysis of CFD Solutions from the Fourth AIAA Drag Prediction Workshop," AIAA Paper 2010-4673, June 2010.

${ }^{13}$ Rivers, M.B. and Dittberner, A., "Experimental Investigations of the NASA Common Research Model in the NASA Langley National Transonic Facility and the NASA Ames 11-Ft Transonic Wind Tunnel (Invited)," AIAA Paper 2011-1126, January 2011.

${ }^{14}$ Gloss, B. B., "Current Status and Some Future Test Directions for the US National Transonic Facility. Wind Tunnels and Wind Tunnel Test Techniques," Royal Aeronautical Society, 1992, pp. 3.1-3.7.

${ }^{15}$ Fuller, D. E., "Guide for Users of the National Transonic Facility,” NASA TM-83124, 1981.

${ }^{16}$ Kmak, F., "Modernization and Activation of the NASA Ames 11-By-11-Foot Transonic Wind Tunnel," AIAA Paper 2000-2680, June 2000 .

${ }^{17}$ Amaya, M.A. and Murthy, S.V., "Flow Quality Measurements in the NASA Ames Upgraded 11-By-11-Foot Transonic Wind Tunnel (invited Paper)," AIAA Paper 2000-2681, June 2000.

${ }^{18}$ J. C. Vassberg, M. A. DeHaan, S. M. Rivers, and R. A. Wahls. "Development of a Common Research Model for Applied CFD validation studies.” AIAA Paper 2008-6919, 26th AIAA Applied Aerodynamics Conference, Hawaii, HI, August 2008.

${ }^{19}$ Rivers, M.B., and Dittberner, A., "Experimental Investigation of the NASA Common Research Model (Invited)," AIAA Paper 2010-4218, June 2010.

${ }^{20}$ Ulbrich, N. and Lo, C., "A Wall Interference Assessment/Correction System," Semi-Annual Report \#1, The University of Tennessee Space Institute, December 1991.

${ }^{21}$ Ulbrich, N., Lo, C., and Steinle, Jr., F., "Blockage Correction in Three-Dimensional Wind Tunnel Testing Based on the Wall Signature Method," July 6-8 1992, Presented at the AIAA 17th Aerospace Ground Testing Conference, AIAA Paper 92-3925.

${ }^{22}$ Ulbrich, N. and Steinle, Jr., F., "Real-Time Wall Interference Calculation in Three-Dimensional Subsonic Wind Tunnel Testing," January 10-13 1994, Presented at the 32nd Aerospace Sciences Meeting and Exhibit, AIAA Paper 940771 .

${ }^{23}$ Ulbrich, N. and Steinle, Jr., F., "Semispan Model Wall Interference Prediction Based on the Wall Signature Method," January 9-12 1995, Presented at the 33rd Aerospace Sciences Meeting and Exhibit, AIAA Paper 95-0793.

${ }^{24}$ Ulbrich, N. and Boone, A., Real-Time Wall Interference Correction System of the 12FT Pressure Wind Tunnel," January 12-15 1998, Presented at the 36th Aerospace Sciences Meeting and Exhibit, AIAA Paper 98-0707.

${ }^{25}$ Ulbrich, N., "The Real-Time Wall Interference Correction System of the NASA Ames 12-Foot Pressure Tunnel," NASA CR 1998-208537, 1998.

${ }^{26}$ Ulbrich, N. and Boone, A., "Determination of the Wall Boundary Condition of the NASA Ames 11FT Transonic Wind Tunnel," January 8-11 2001, Presented at the 39th Aerospace Sciences Meeting and Exhibit, AIAA Paper 20011112 . 
${ }^{27}$ Ulbrich, N. and Boone, A., "Direct Validation of the Wall Interference Correction System of the Ames 11-Foot Transonic Wind Tunnel," May 2003, NASA/TM-2003-212268.

${ }^{28}$ Hackett, J. and Wilsden, D., "Determination of Low Speed Wake Blockage Corrections Via Tunnel Wall Static Pressure Measurements," Wind Tunnel Design and Testing Techniques, March 1976, AGARD-CP-174. Presented to the AGARD Fluid Dynamics Panel Symposium on Wind Tunnel Design and Testing Techniques: London, England, 6-8 October 1975.

${ }^{29}$ Hackett, J. and Boles, R., "Wake Blockage Corrections and Ground Effect Testing in Closed Wind Tunnels," Journal of Aircraft, Vol. 13, No. 8, August 1976, pp. 597ñ604.

${ }^{30}$ Hackett, J. and Wilsden, D., "Estimation of Wind Tunnel Blockage from Wall Pressure Signatures: A Review of Recent Work at Lockheed-Georgia," AIAA Paper 78-828, April 1978.

${ }^{31}$ Hackett, J., Wilsden, D., and Lilley, D., "Estimation of Tunnel Blockage from Wall Pressure Signatures: A Review and Data Correlation," NASA CR 15224, March 1979.

${ }^{32}$ Hackett, J., Wilsden, D., and Stevens, W., "A Review of the 'Wall Pressure Signature' and Other Tunnel Constraint Correction Methods for High Angle-of-Attack Tests," AGARD R692, February 1981, Presented to the AGARD Fluid Dynamics Panel Round Table Discussion on Wind Tunnel Corrections for High Angle-of-Attack Models: Munich, FRG, 8 May 1980.

${ }^{33}$ Iyer, V., Everhart, J., Bir, P., and Ulbrich, N., "Implementation of the WICS Wall Interference Correction System at the National Transonic Facility," June 19-22 2000, Presented at the 21st AIAA Aerodynamic Measurement Technology and Ground Testing Conference, Denver, CO, AIAA Paper 2000-2383.

${ }^{34}$ Iyer, V. and Everhart, J., "Application of Pressure-Based Wall Correction Methods to Two NASA Langley Wind Tunnels," June 11-14 2001, Presented at the 19th AIAA Applied Aerodynamics Conference, Anaheim, CA, AIAA Paper 2001-2472.

${ }^{35}$ Ulbrich, N., "The Representation of Wind Tunnel Model Blockage Effects Using Point Doublets," January 14-17 2002, Presented at the 40th Aerospace Sciences Meeting and Exhibit, AIAA Paper 2002-0880.

${ }^{36}$ Walker, E., Statistical Calibration and Validation of a Homogeneous Ventilated Wall-Interference Correction Method for the National Transonic Facility, Ph.D. thesis, Virginia Polytechnic Institute and State University, October 2005, Available electronically at http://scholar.lib.vt.edu/theses/available/etd-10272005-165559/. Also available as NASA/TP 2005-213947, 2005.

${ }^{37}$ Pirzadeh, S. “Advanced Unstructured Grid Generation for Complex Aerodynamics Applications”. AIAA-20087178, August 2008.

${ }^{38}$ Pandya, M., Abdol-Hamid, K., and Frink, N. "Enhancement of USM3D Unstructured Flow Solver for Highspeed High-Temperature Shear Flows". AIAA-2009-1329, January 2009.

${ }^{39}$ Pandya, M., Abdol-Hamid, K., Campbell, R., and Frink, N. "Implementation of Flow Tripping Capability in the USM3D Unstructured Flow Solver”. AIAA-2006-919, January 2006.

${ }^{40}$ Pandya, M., Frink, N., and Noack, R. "Progress Toward Overset-Grid Moving Body Capability for USM3D Unstructured Flow Solver". AIAA-2005-5118, June 2005.

${ }^{41}$ Pandya, M., Frink, N., Abdol-Hamid, K., and Chung, J. "Recent Enhancements to USM3D Unstructured Flow Solver for Unsteady Flows”. AIAA-2004-5201, August 2004. 


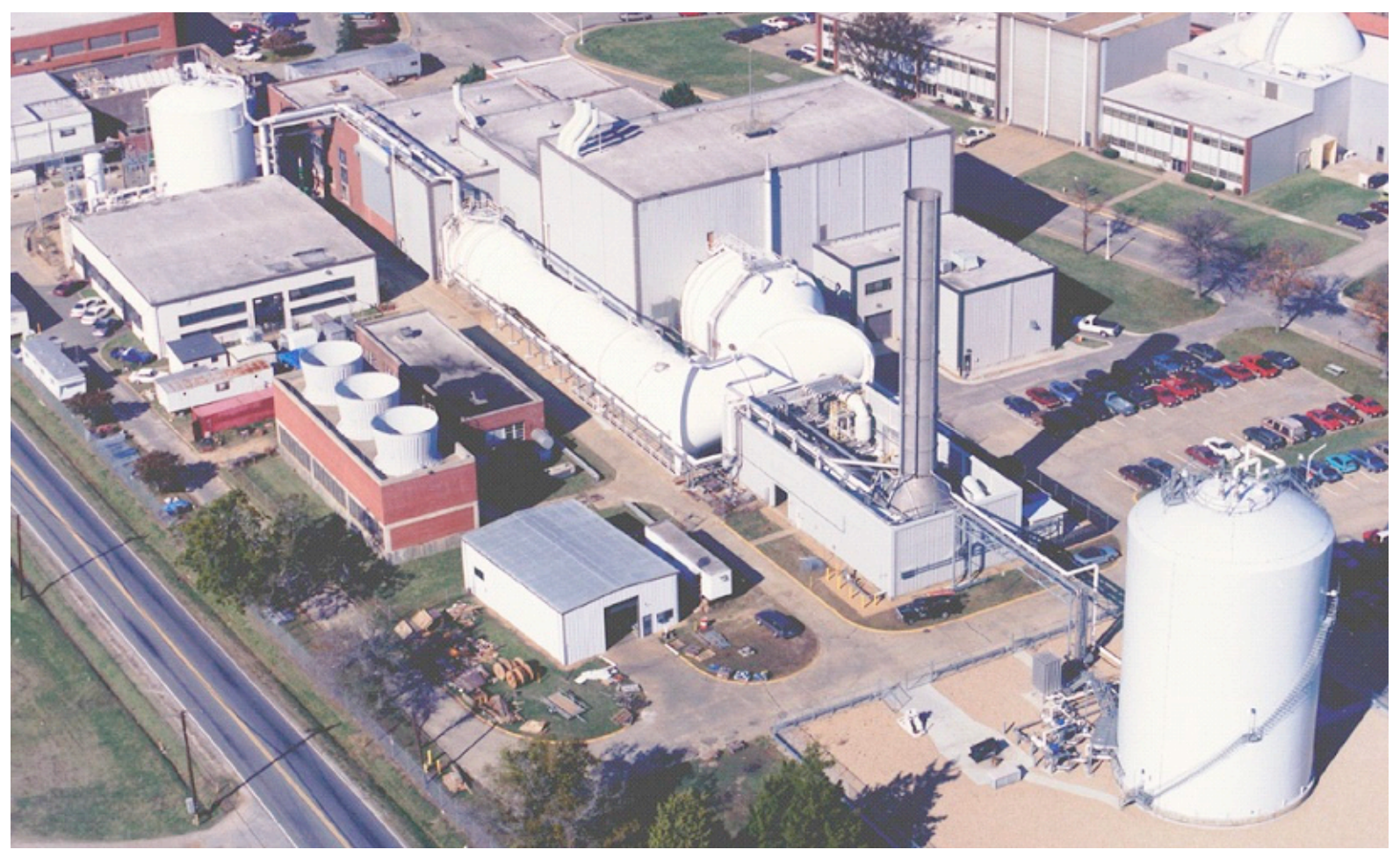

Figure 1. Aerial View of the National Transonic Facility.

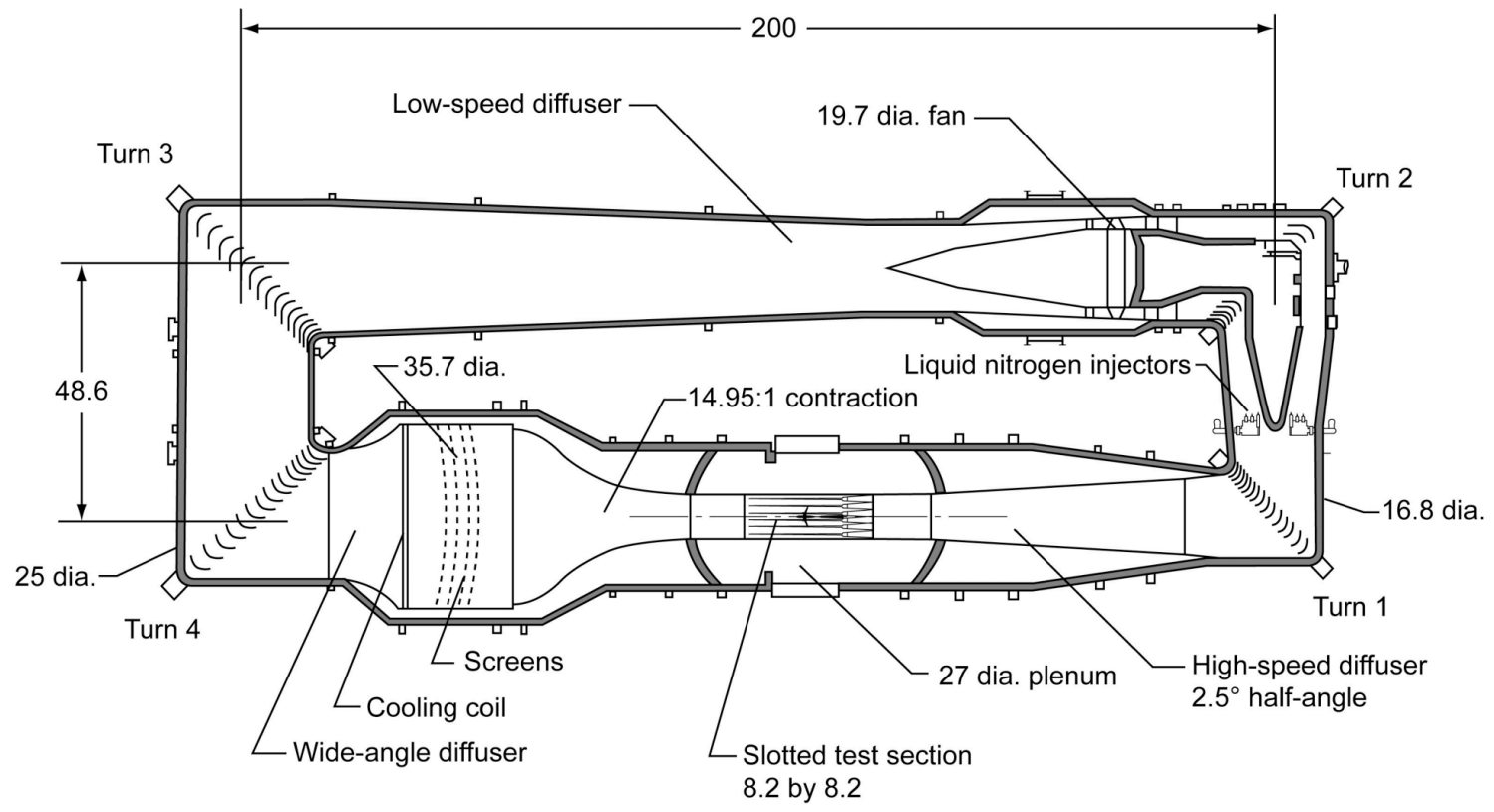

Figure 2. Sketch of the National Transonic Facility tunnel circuit. Linear dimensions are given in feet. 


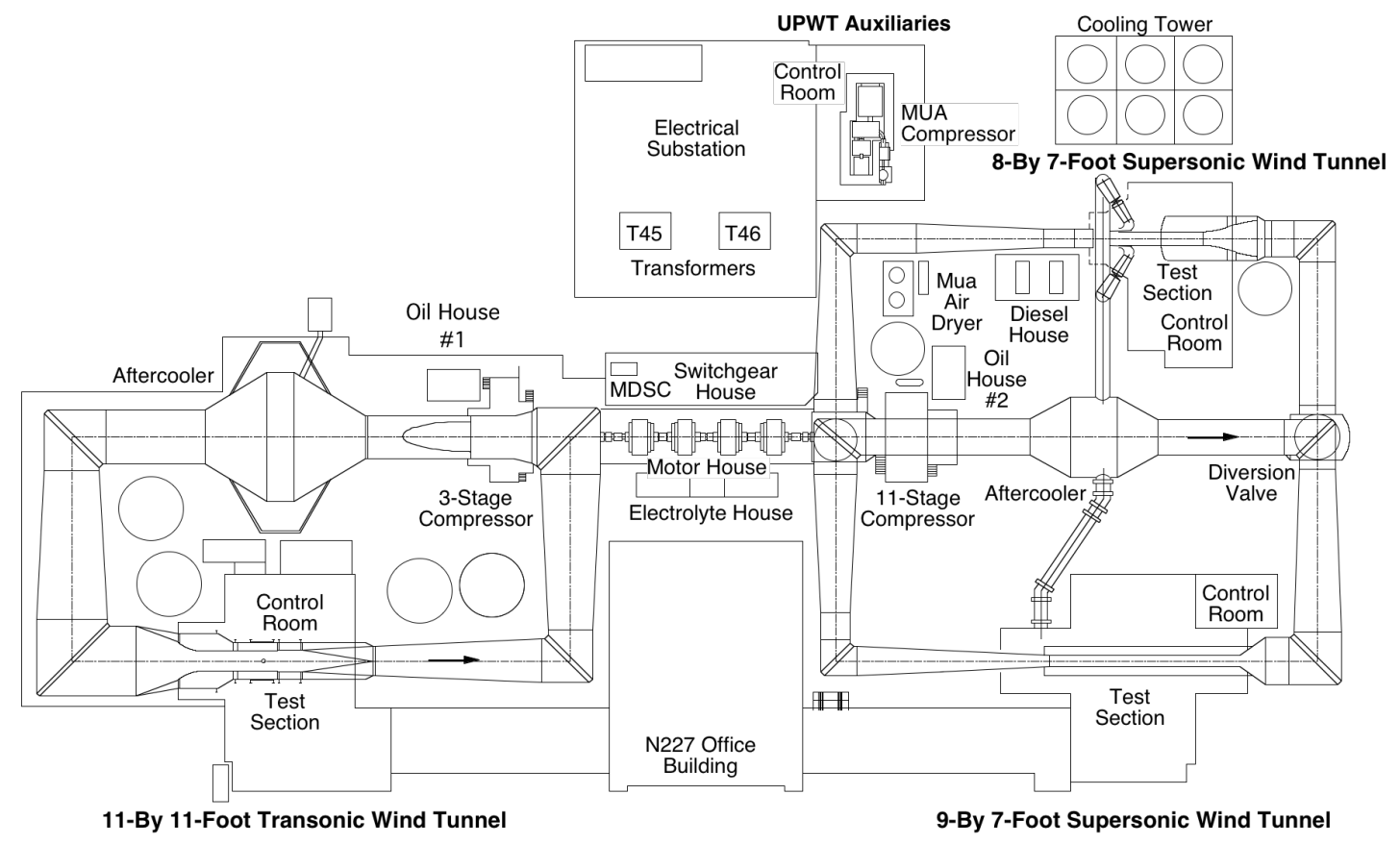

Figure 3. Unitary Plan Wind Tunnel (UPWT) At the NASA Ames Research Center.

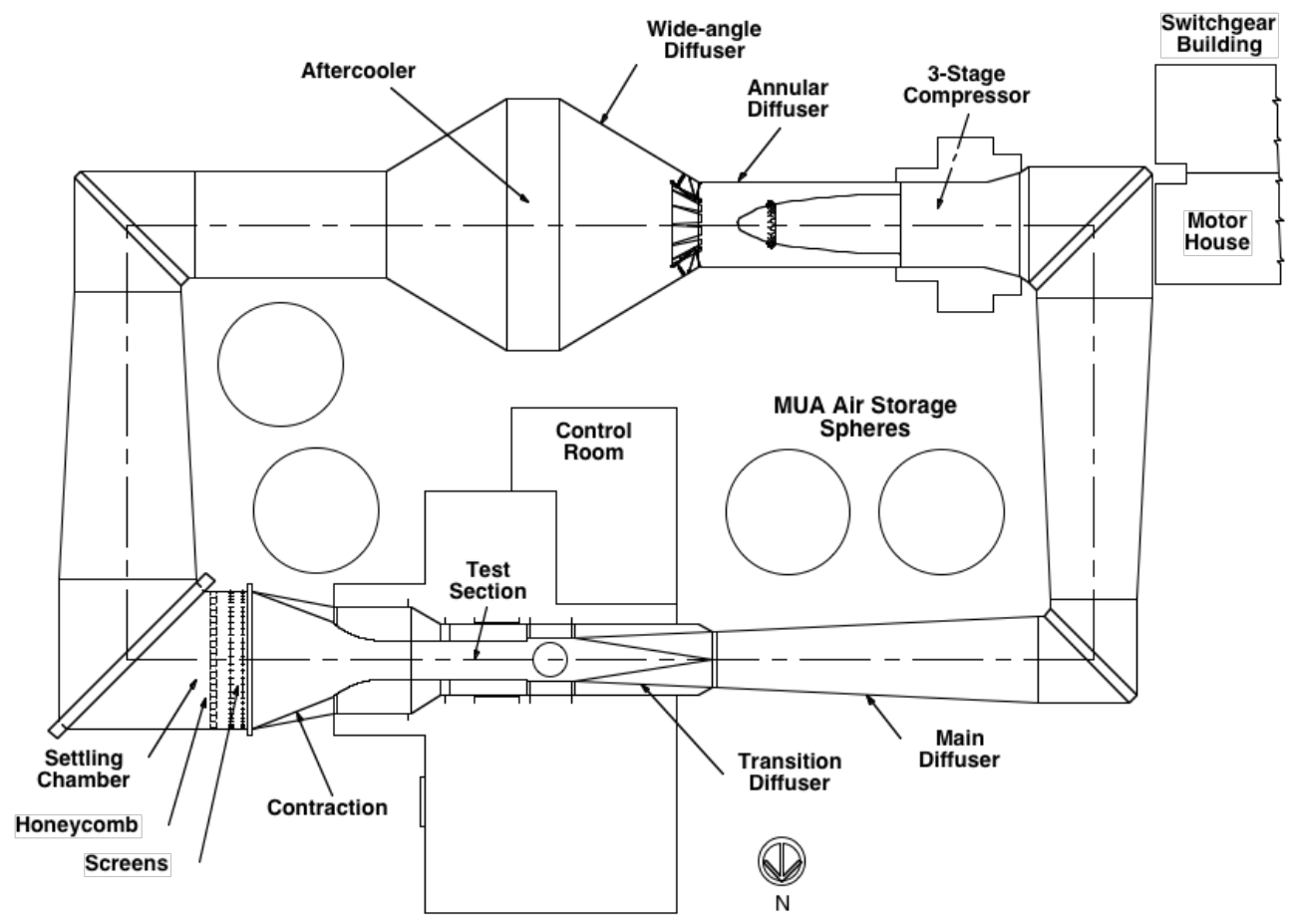

Figure 4. Sketch of the Ames 11-Foot Wind Tunnel. 


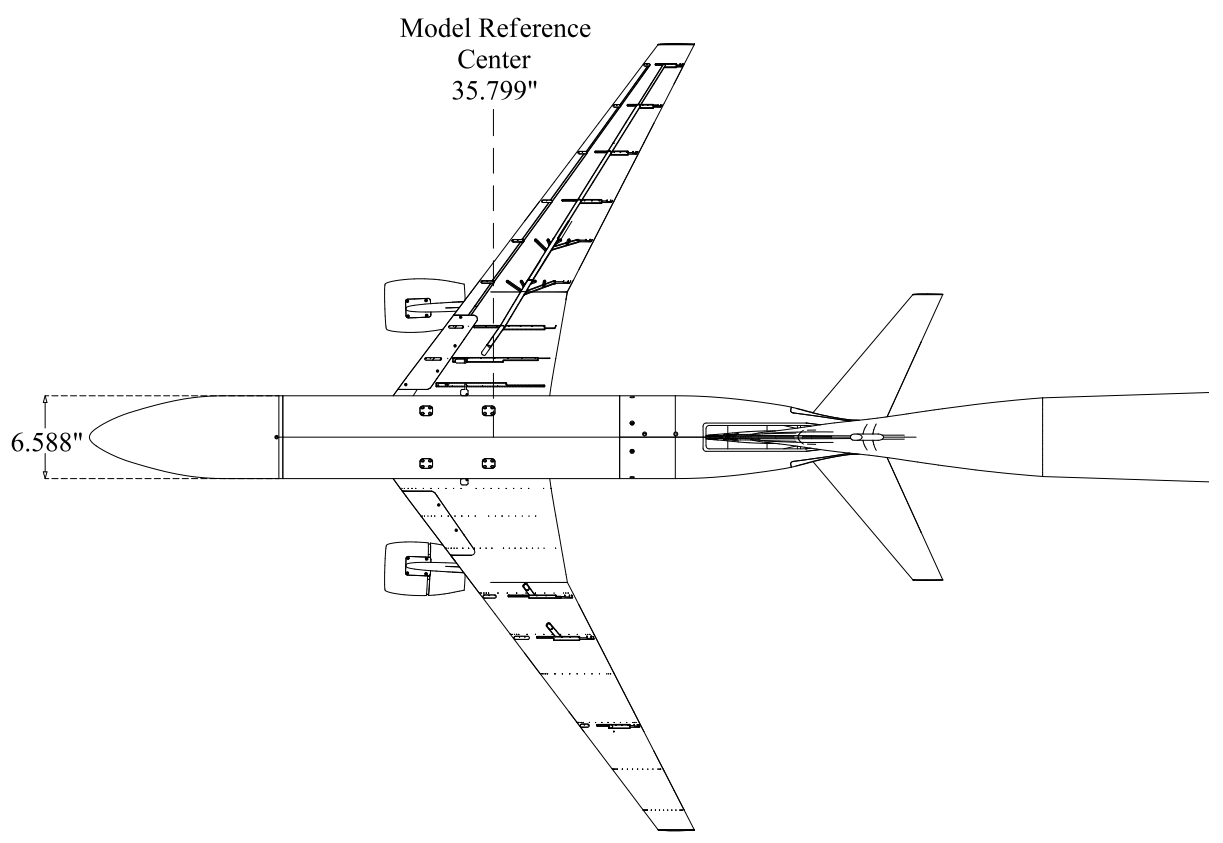

a) Top View

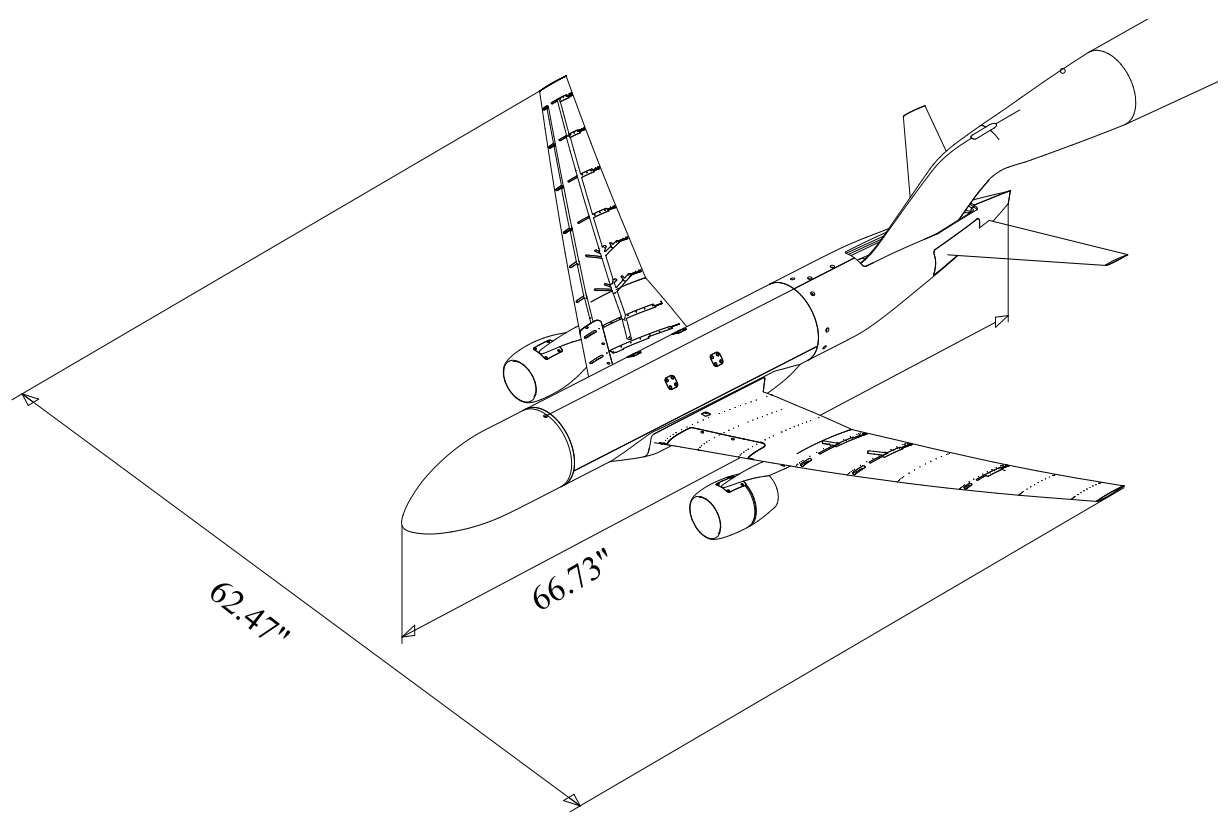

b) Isometric View

Figure 5. Sketch of the Common Research Model with Reference Quantities. 


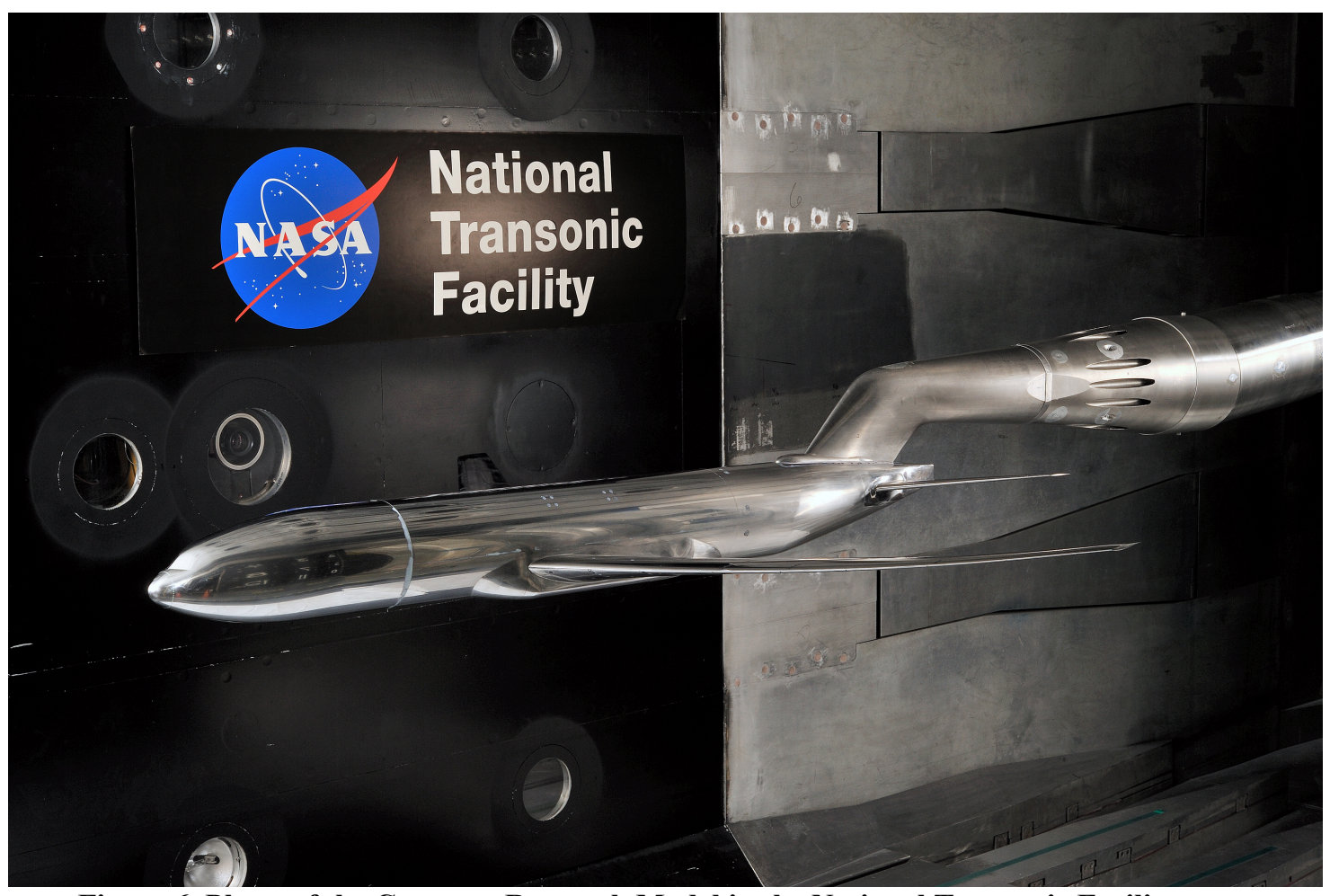

Figure 6. Photo of the Common Research Model in the National Transonic Facility.

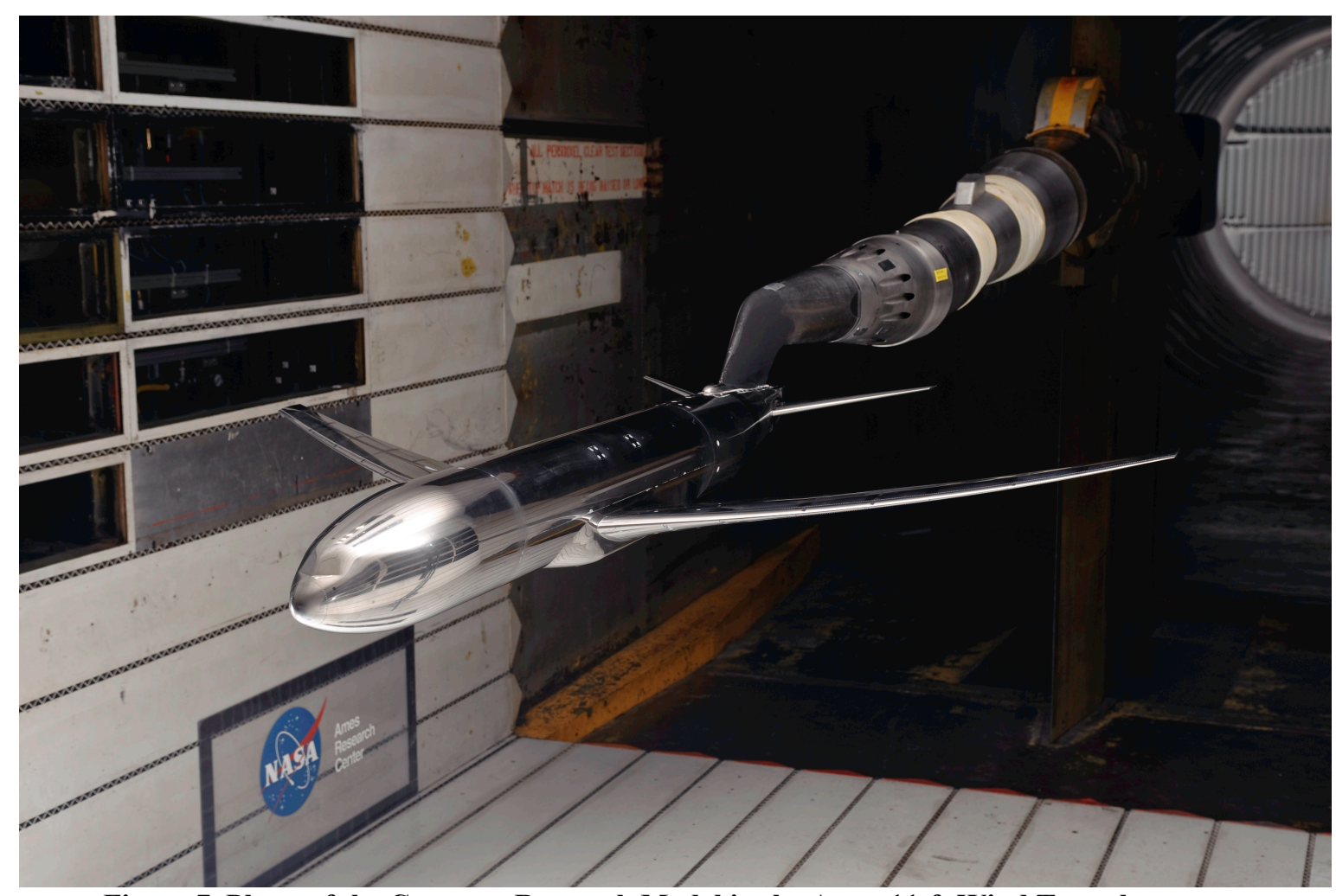

Figure 7. Photo of the Common Research Model in the Ames 11-ft Wind Tunnel. 
NTF Test 197, Run 92

Ames Test 216, Run 77

DPW IV Participant Data
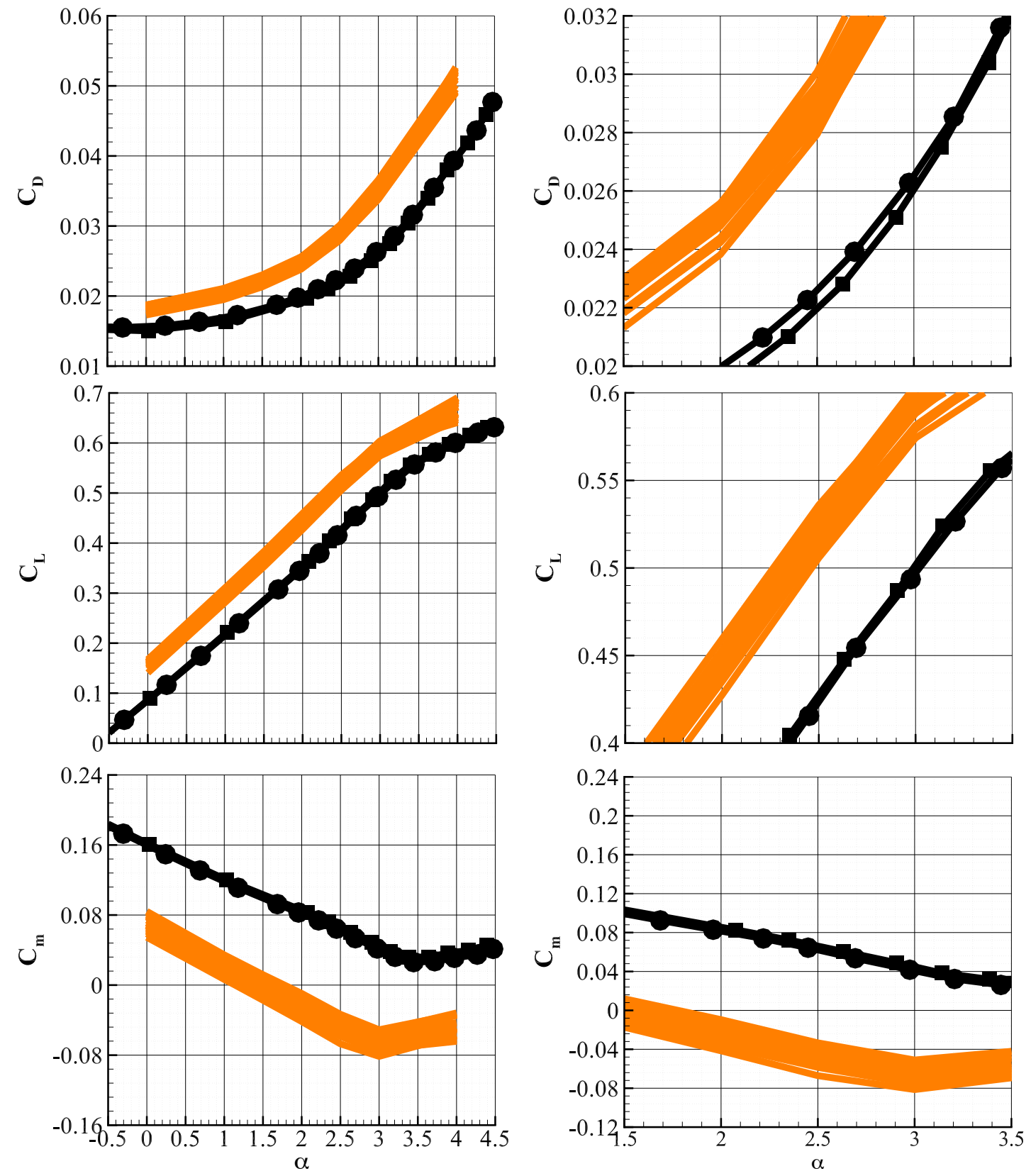

Figure 8. Comparison of NTF and Ames 11-Ft TWT experimental data with DPW IV CFD data for the without support system configuration. 


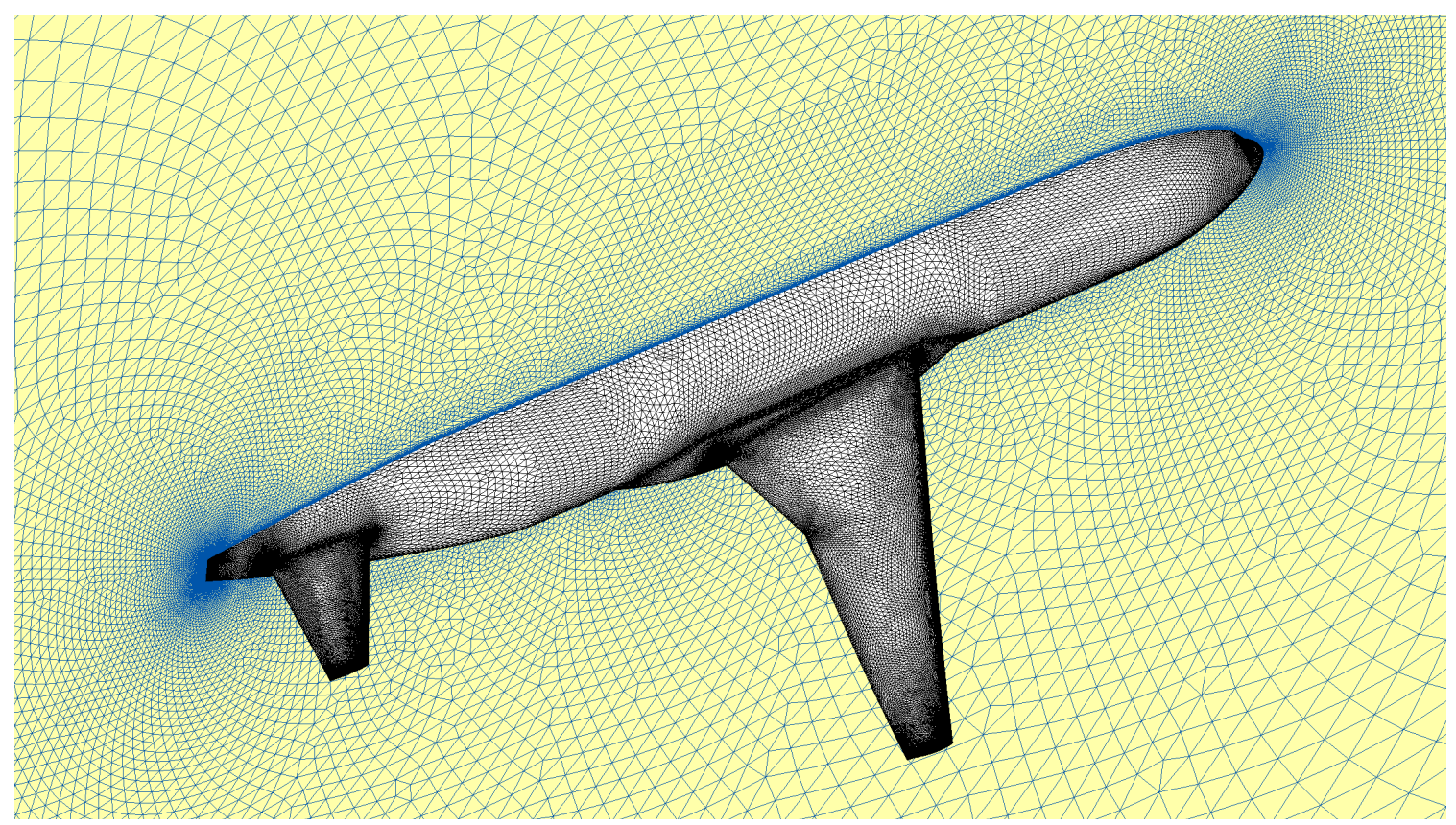

Figure 9. Without support system configuration surface mesh.

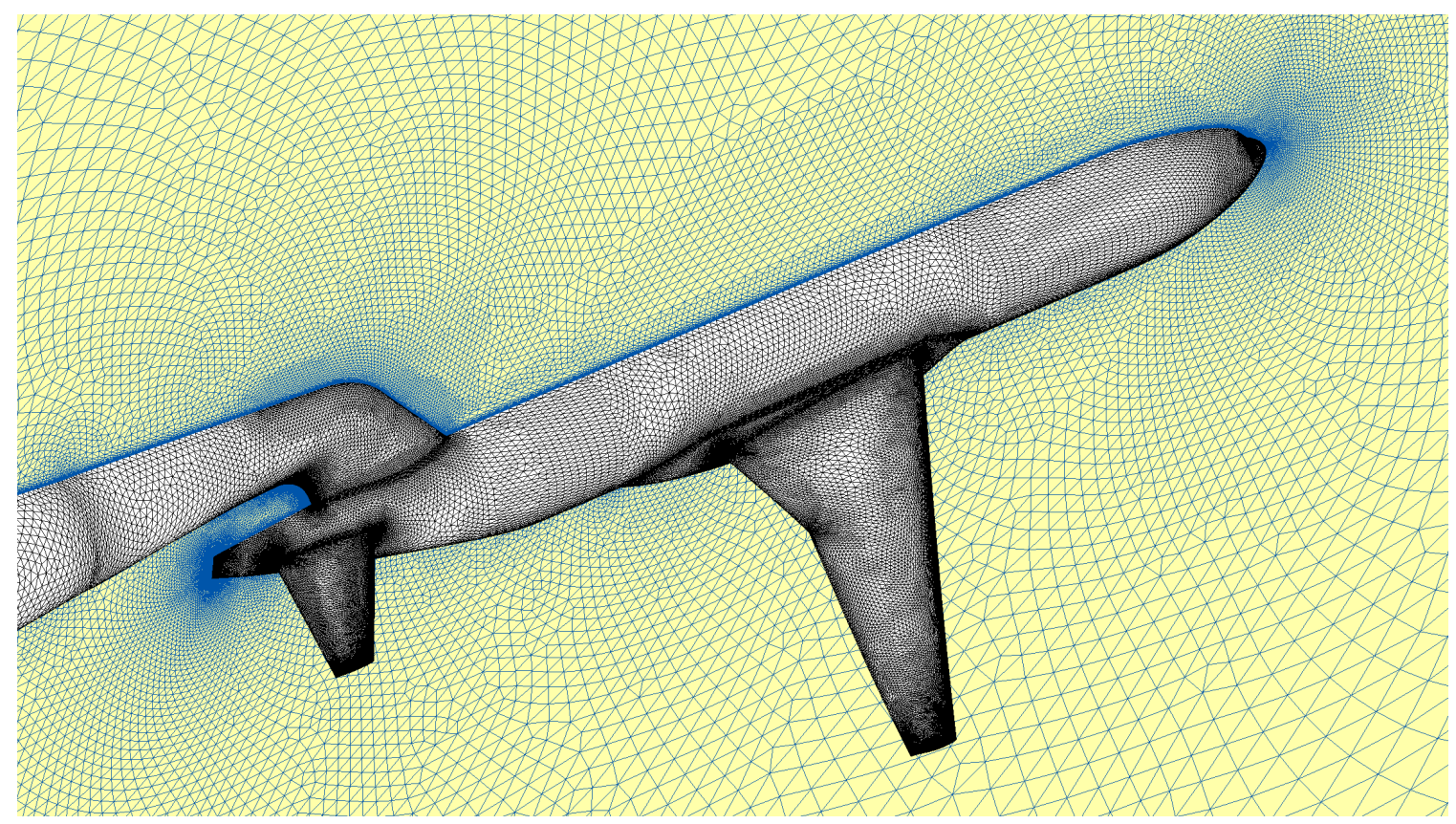

Figure 10. With support system configuration surface mesh. 
Wing/Body/Tail $=0 \mathrm{deg}$

$\mathrm{M}=\mathbf{0 . 8 5}, \alpha=0 \mathrm{deg}, \operatorname{Re}_{\mathrm{c}}=\mathbf{5 \times 1 0 ^ { 6 }}$
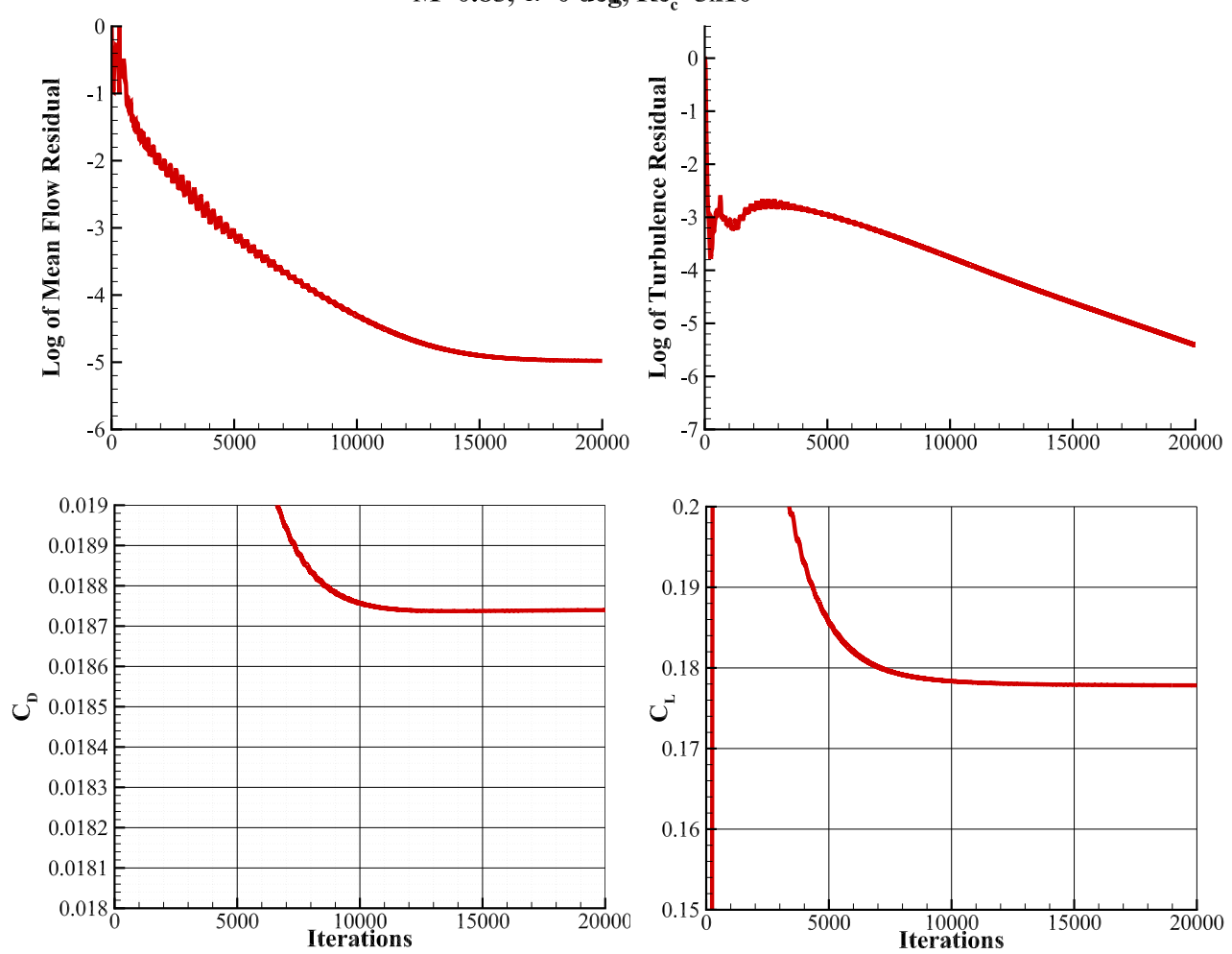

Figure 11. Without support system convergence history, $M_{\infty}=0.85, \alpha=0.0^{\circ}, \operatorname{Re}_{c}=5$ million. 


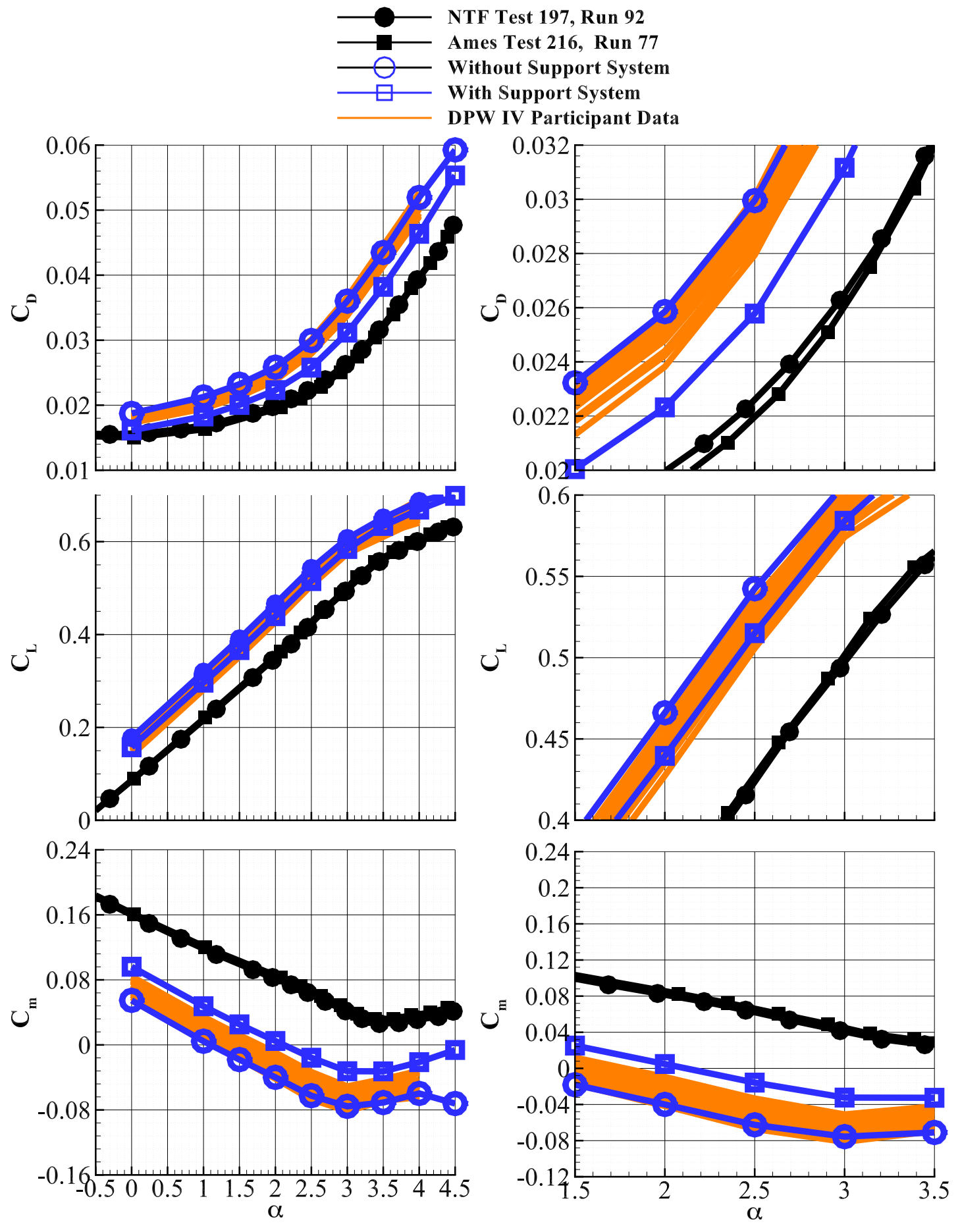

Figure 12. Comparison of NTF and Ames 11-Ft TWT experimental data with USM3D CFD data and DPW IV CFD data for the without support system configuration. 


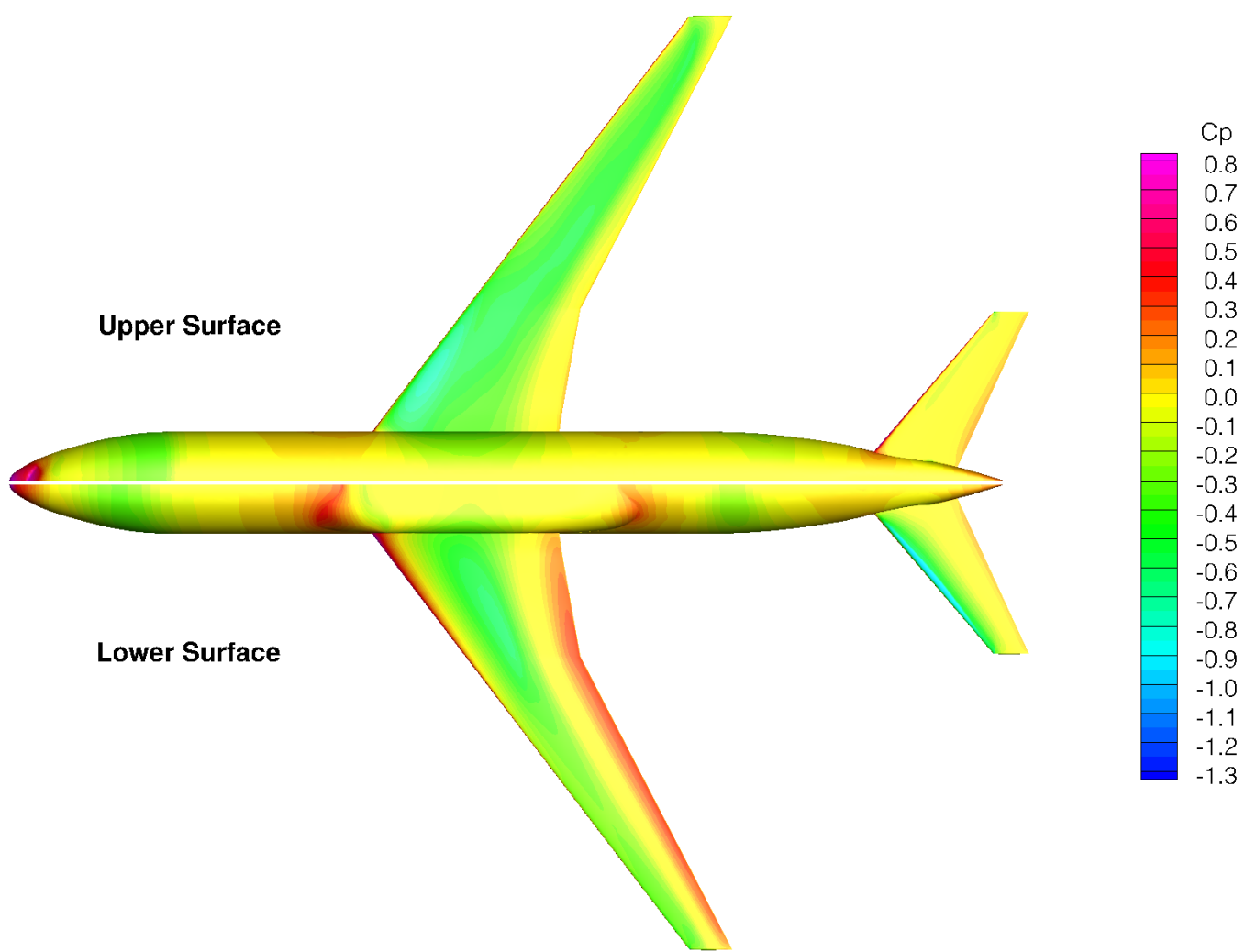

Figure 13. Surface pressure coefficient contours, without support system configuration, $\alpha=0^{\circ}$.

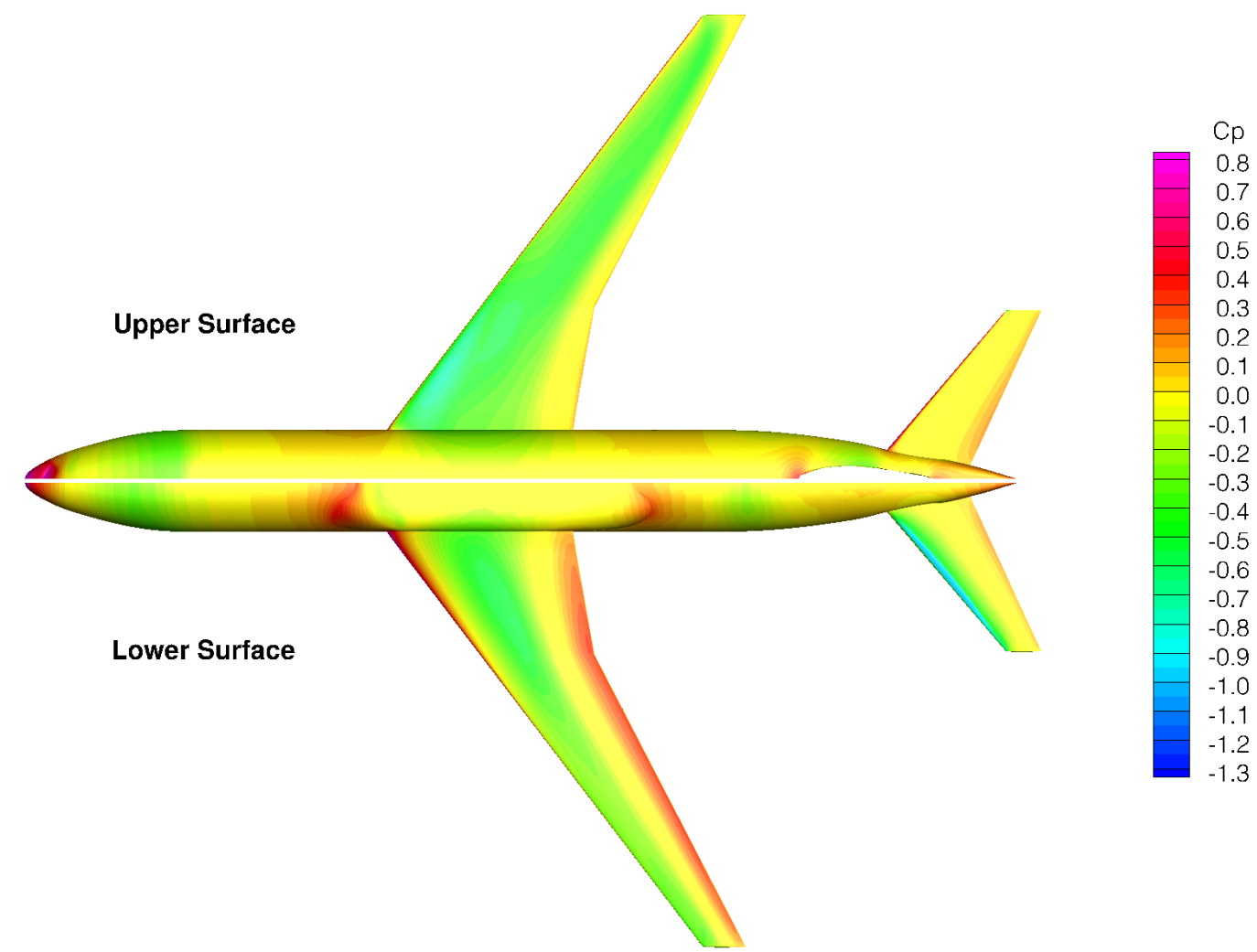

Figure 14. Surface pressure coefficient contours, with support system configuration, $\alpha=0^{\circ}$. 


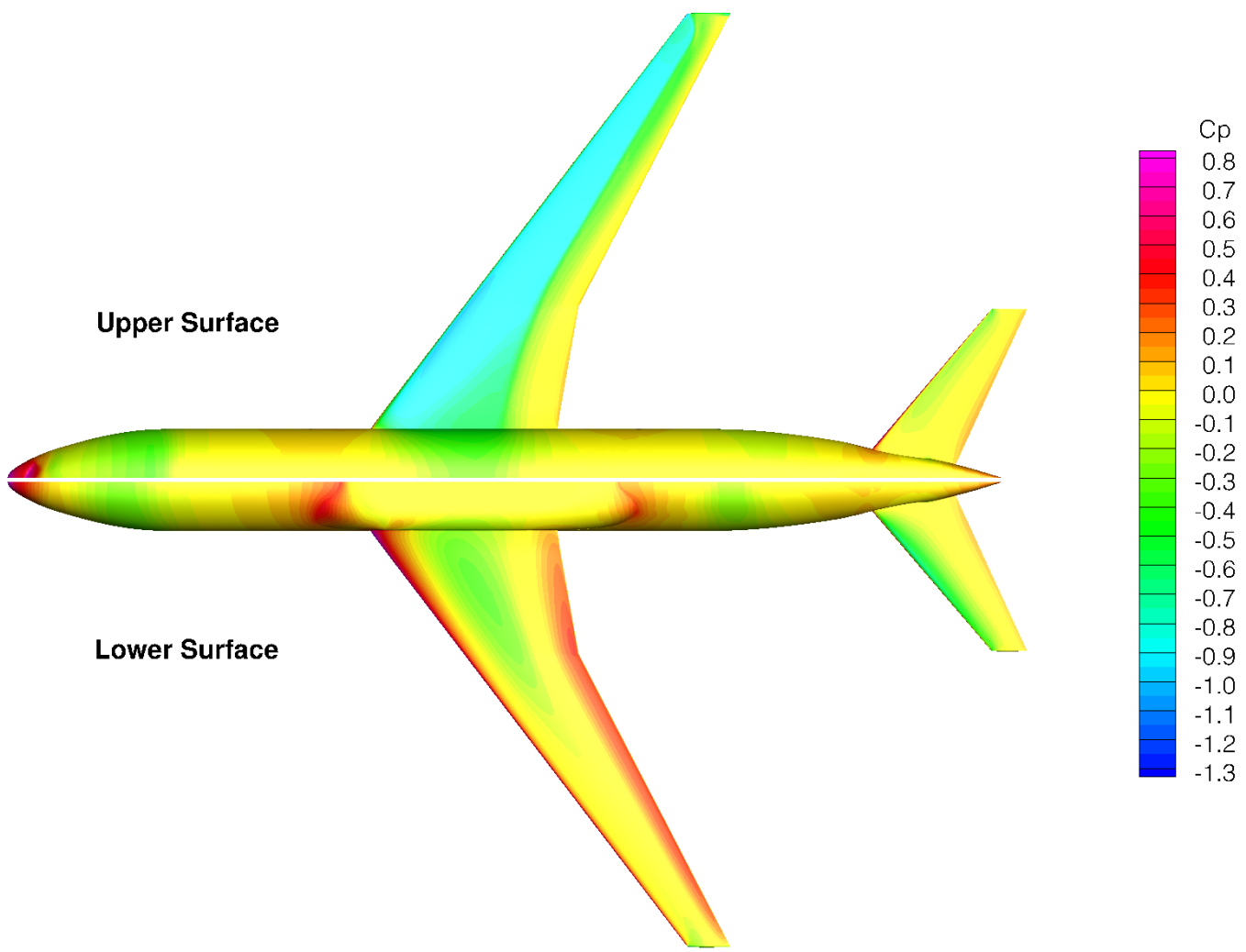

Figure 15. Surface pressure coefficient contours, without support system configuration, $\alpha=2.5^{\circ}$.

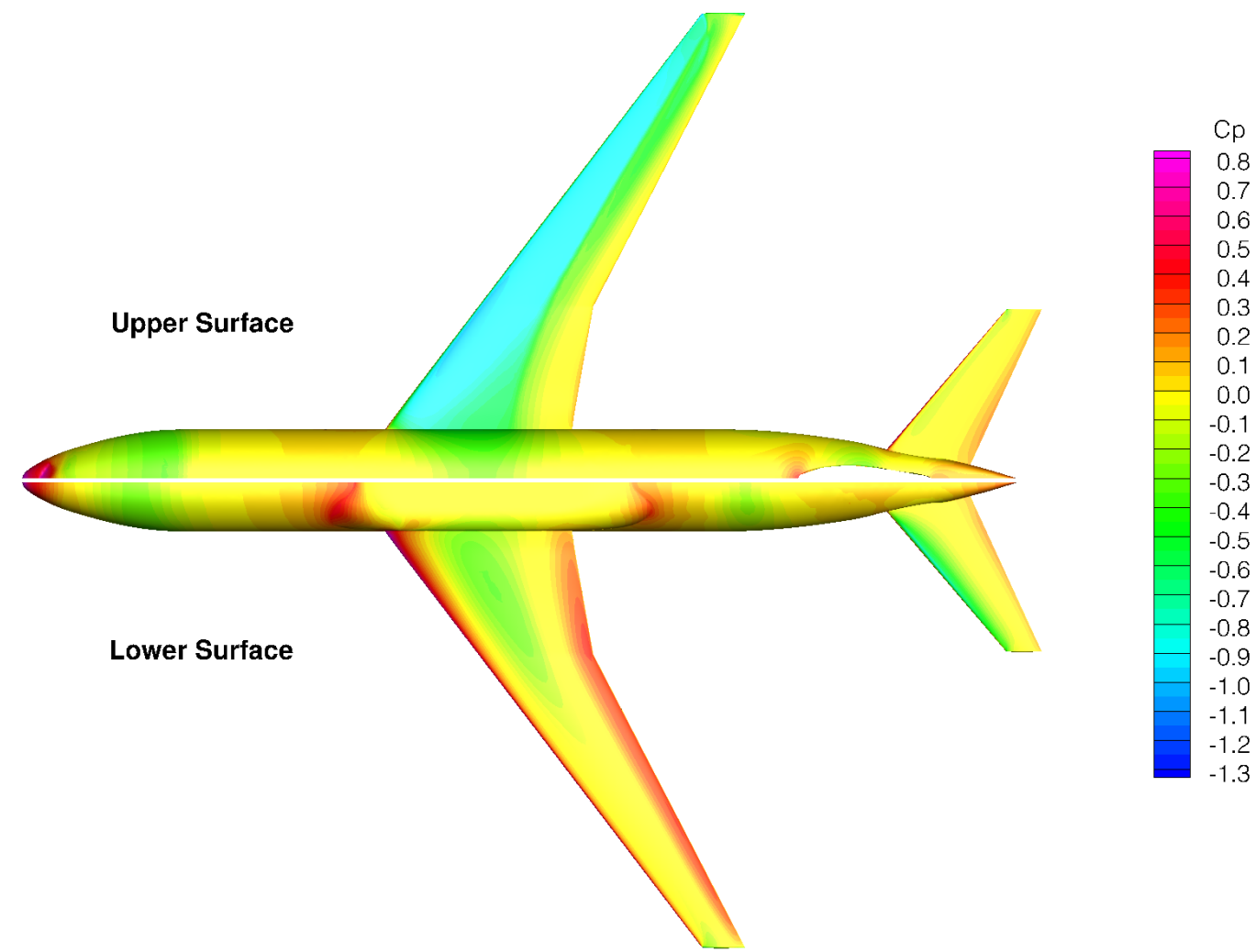

Figure 16. Surface pressure coefficient contours, with support system configuration, $\alpha=2.5^{\circ}$. 


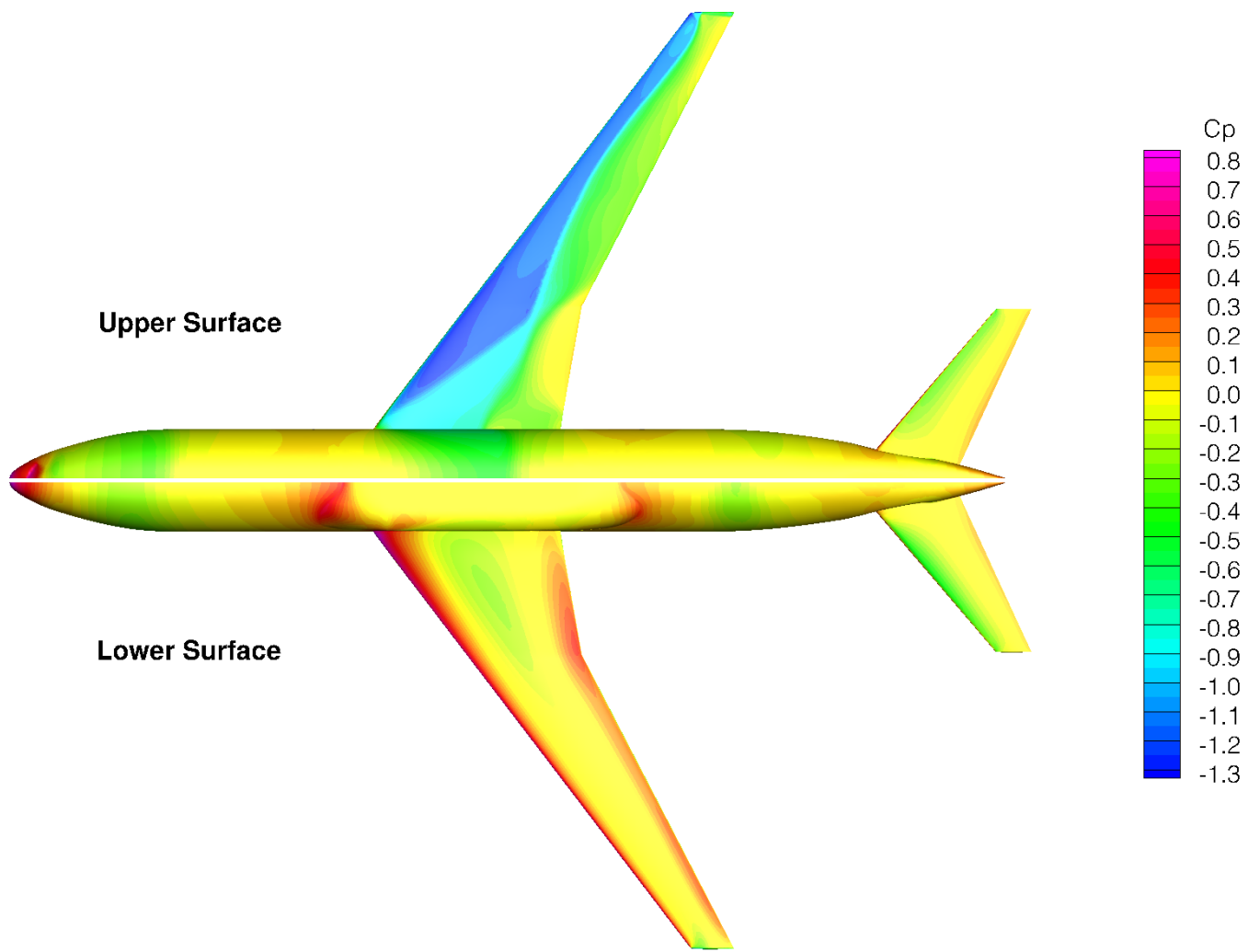

Figure 17. Surface pressure coefficient contours, without support system configuration, $\alpha=5^{\circ}$.

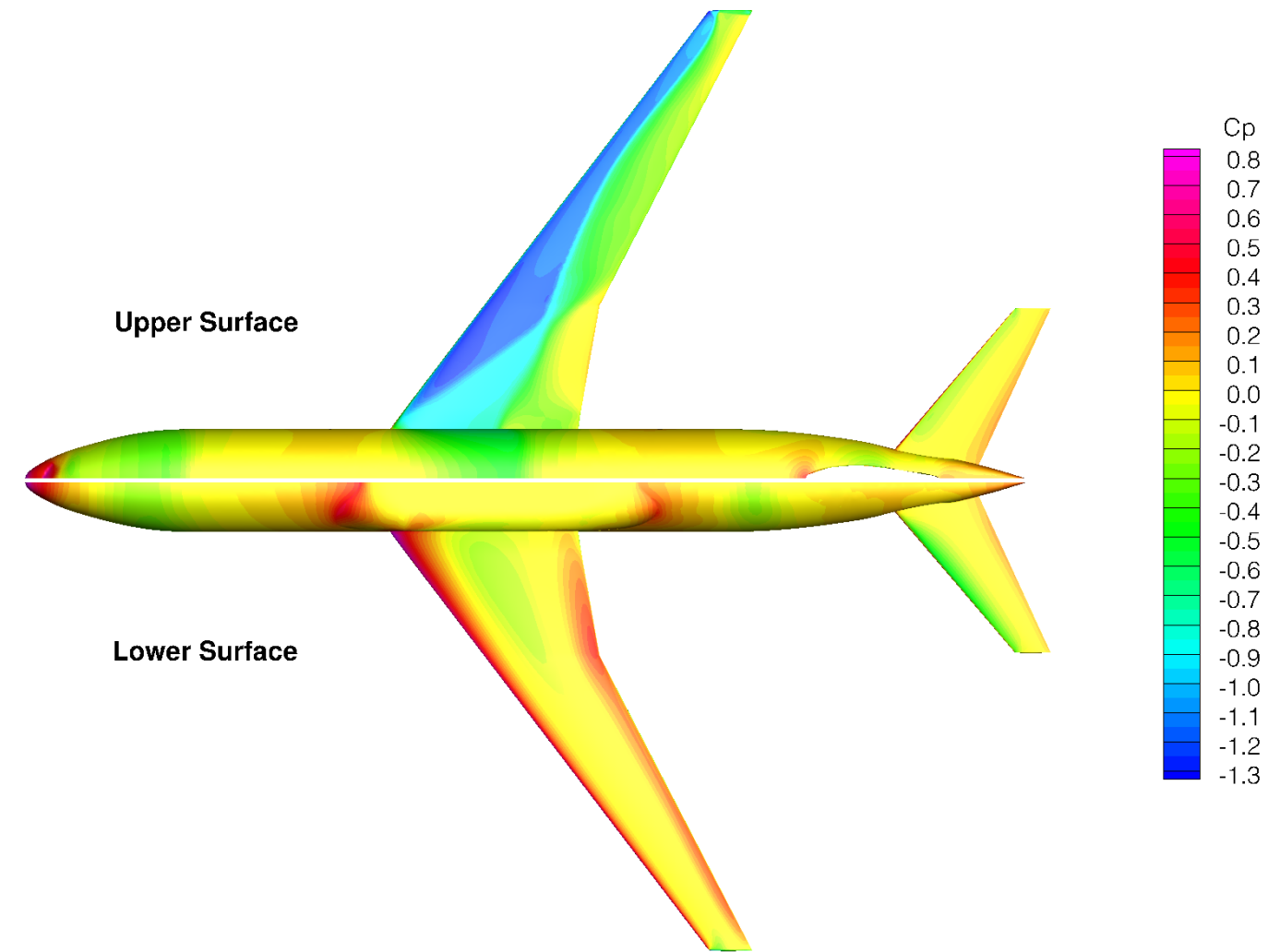

Figure 18. Surface pressure coefficient contours, with support system configuration, $\alpha=5^{\circ}$. 


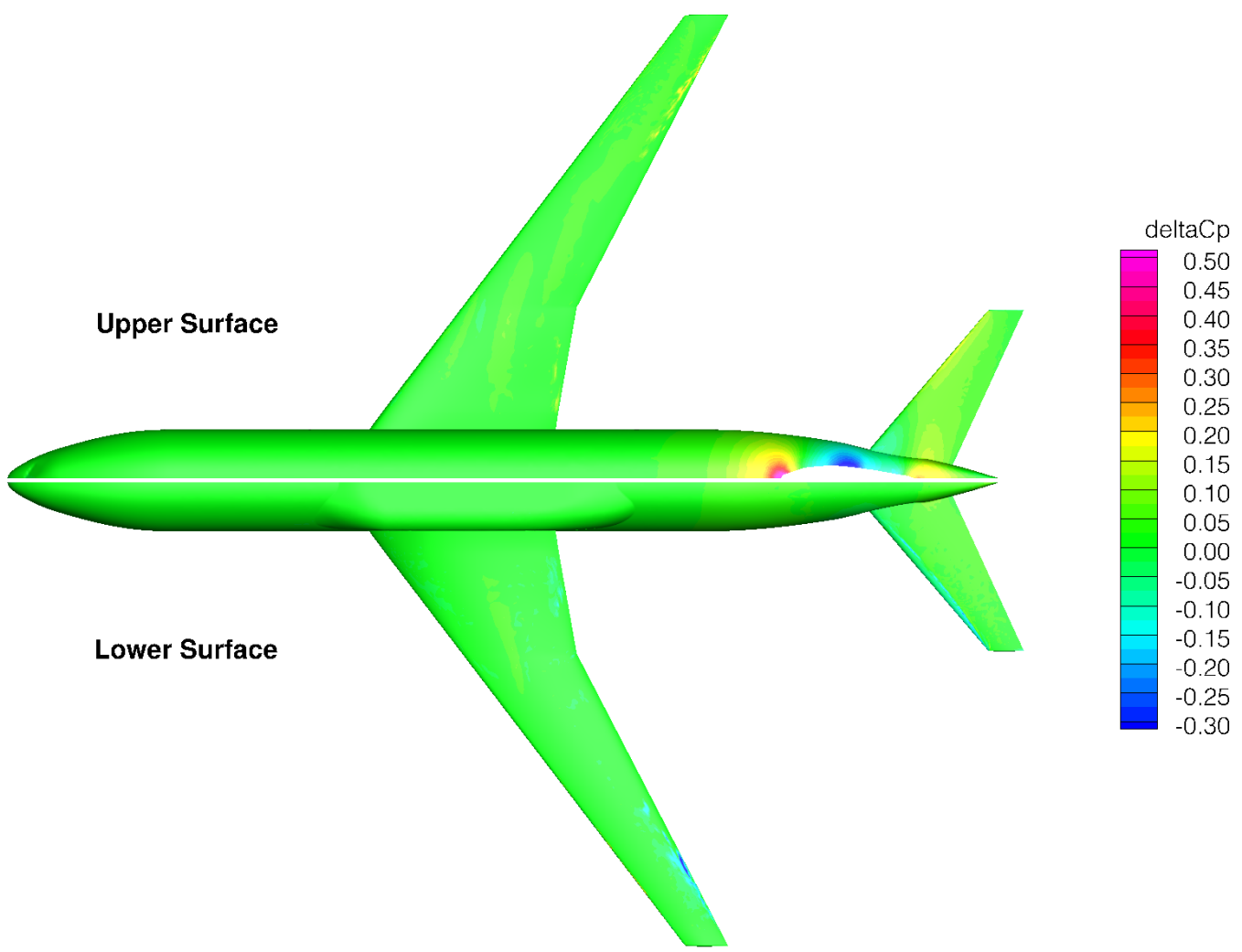

Figure 19. $\Delta C_{P}$ contours at $\alpha=0^{\circ}$.

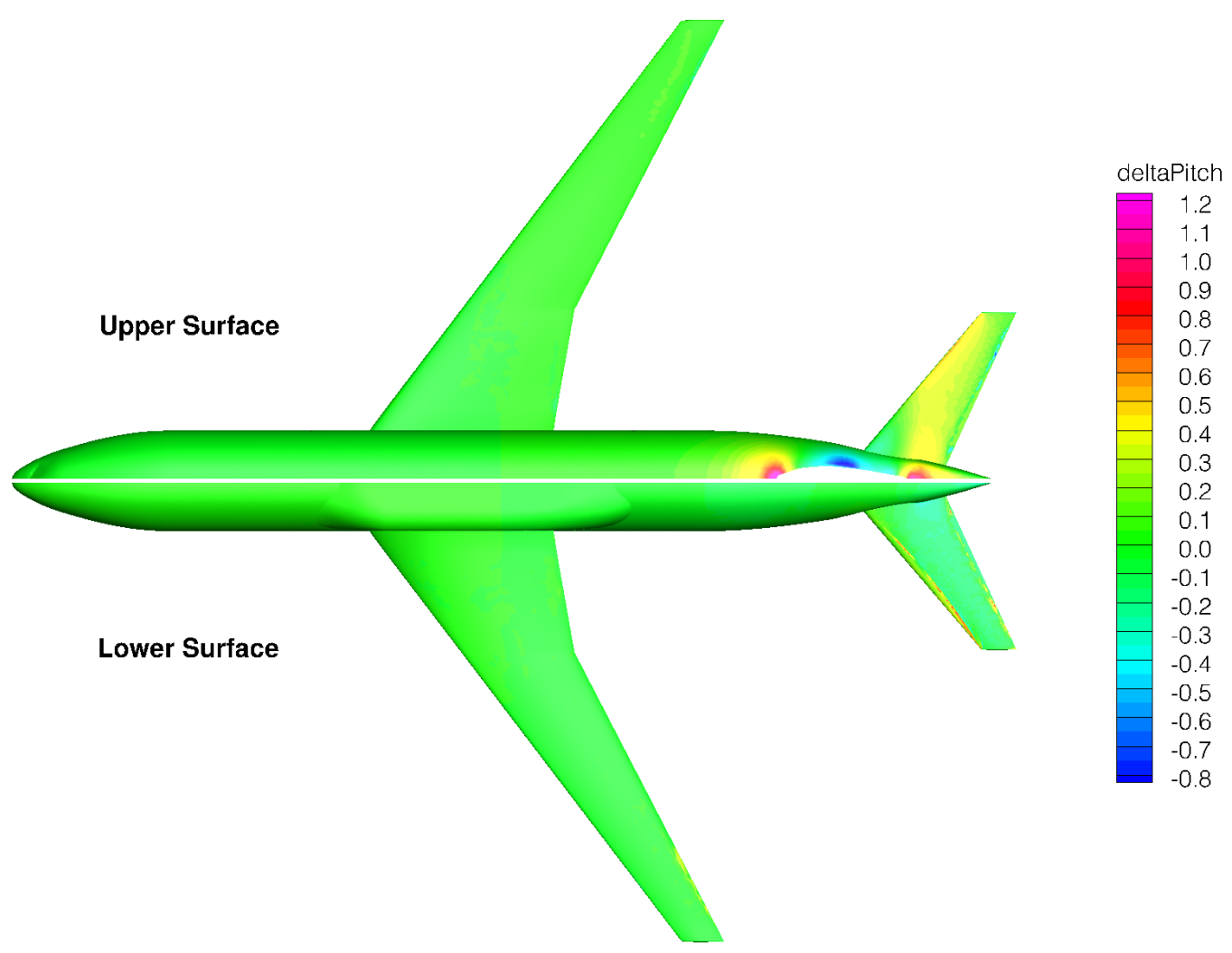

Figure 20. $\delta C_{m}$ contours at $\alpha=0^{\circ}$. 


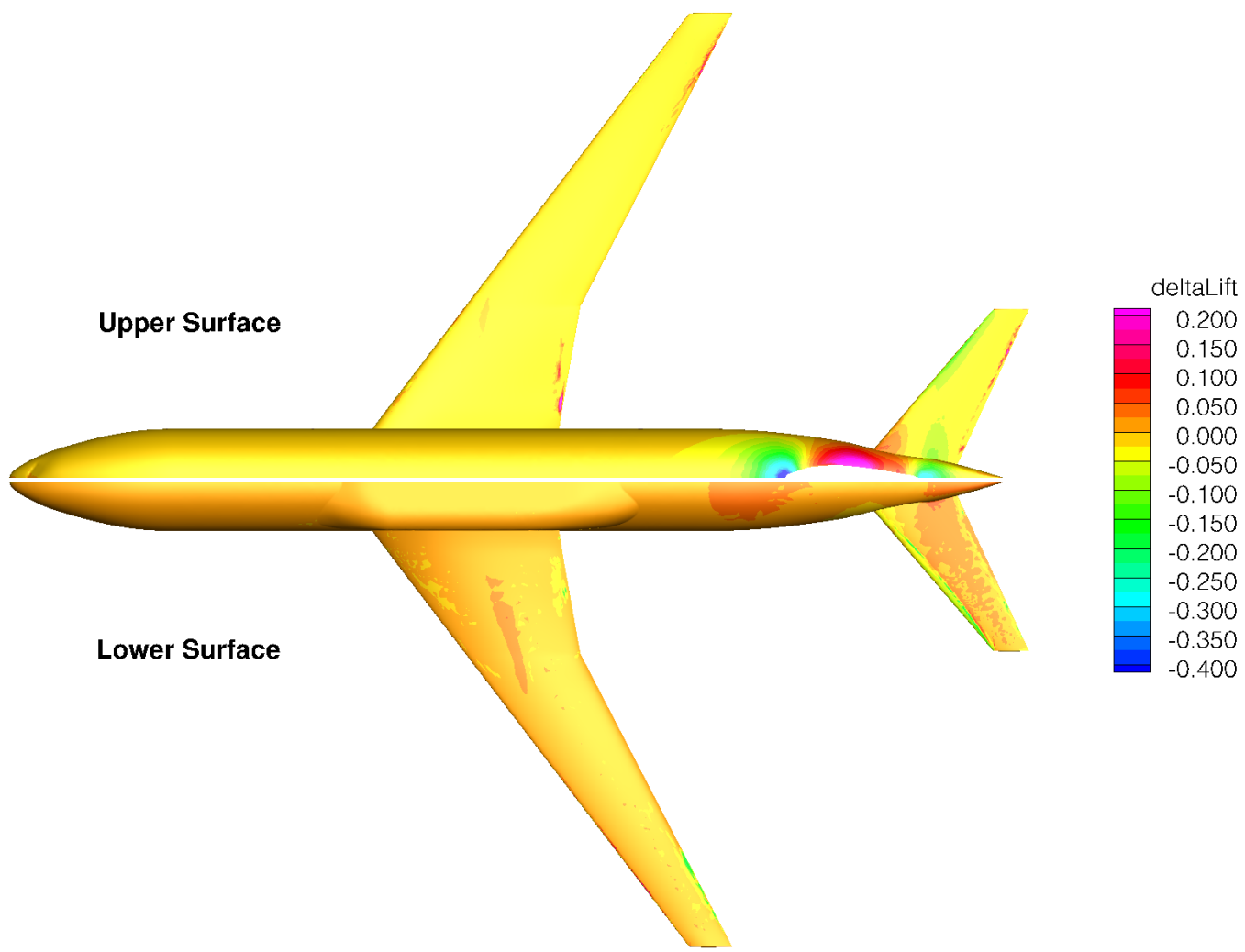

Figure 21. $\delta C_{L}$ contours at $\alpha=0^{\circ}$.

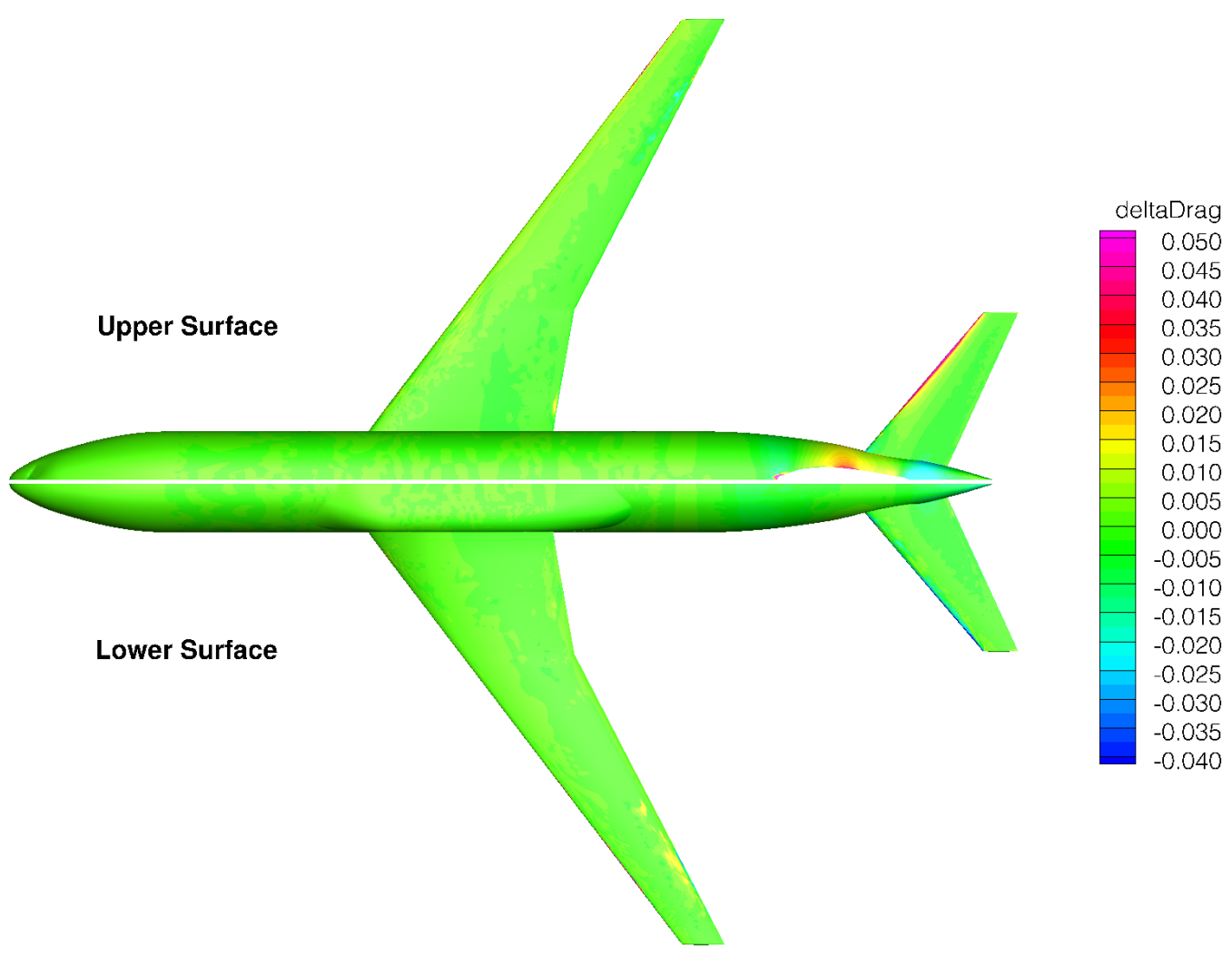

Figure 22. $\delta C_{D}$ contours at $\alpha=0^{\circ}$. 


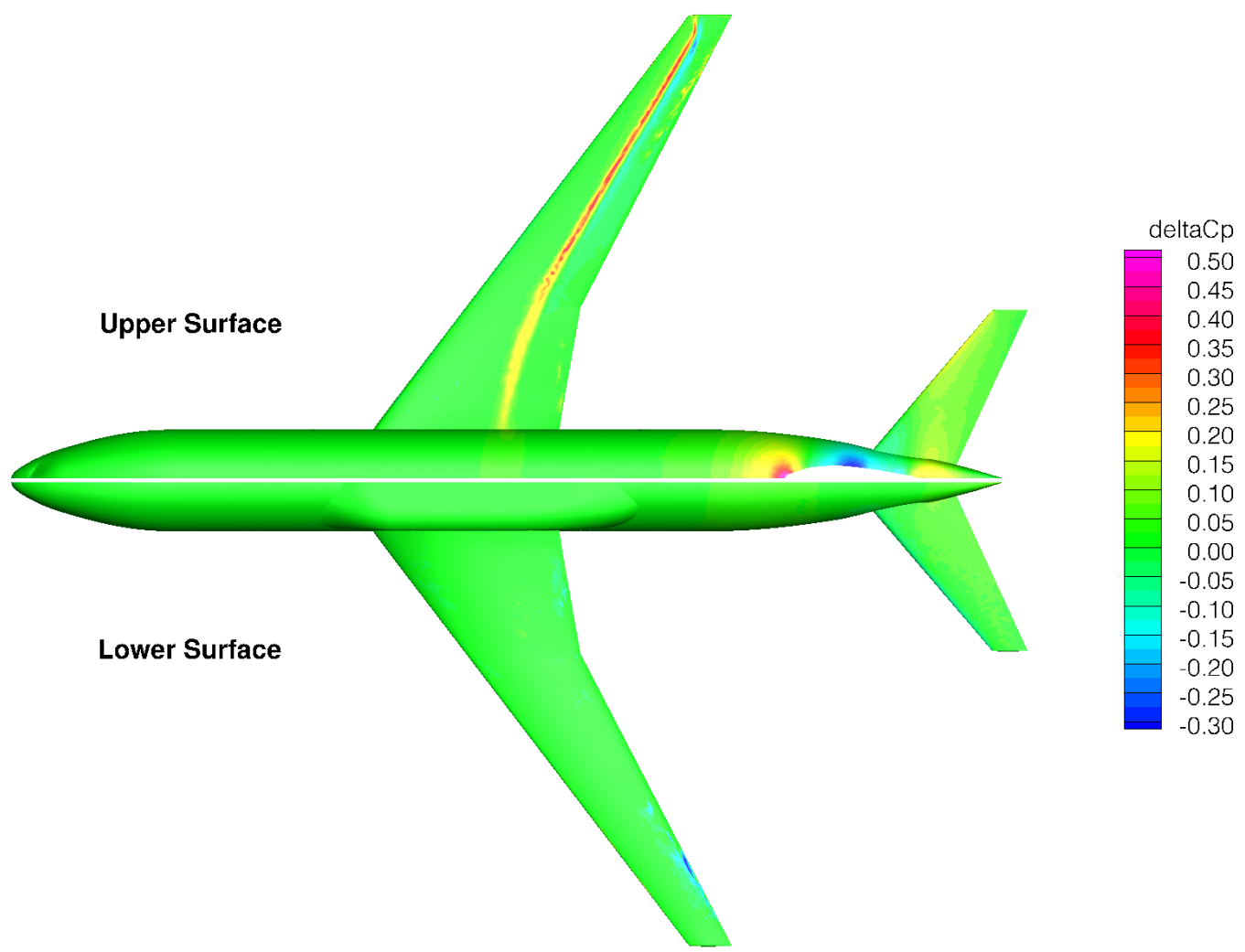

Figure 23. $\Delta C_{P}$ contours at $\alpha=2.5^{\circ}$.

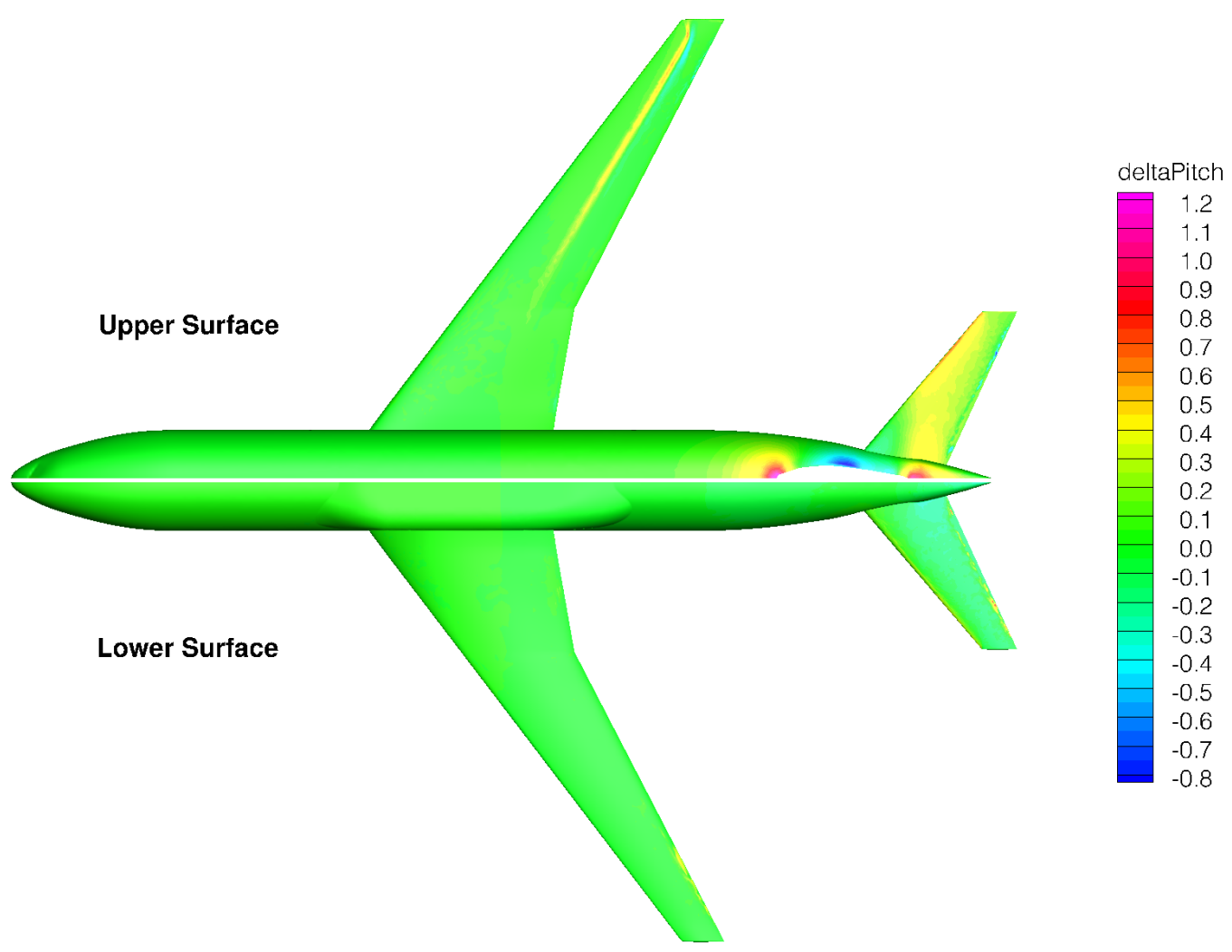

Figure $24 . \delta C_{m}$ contours at $\alpha=2.5^{\circ}$. 


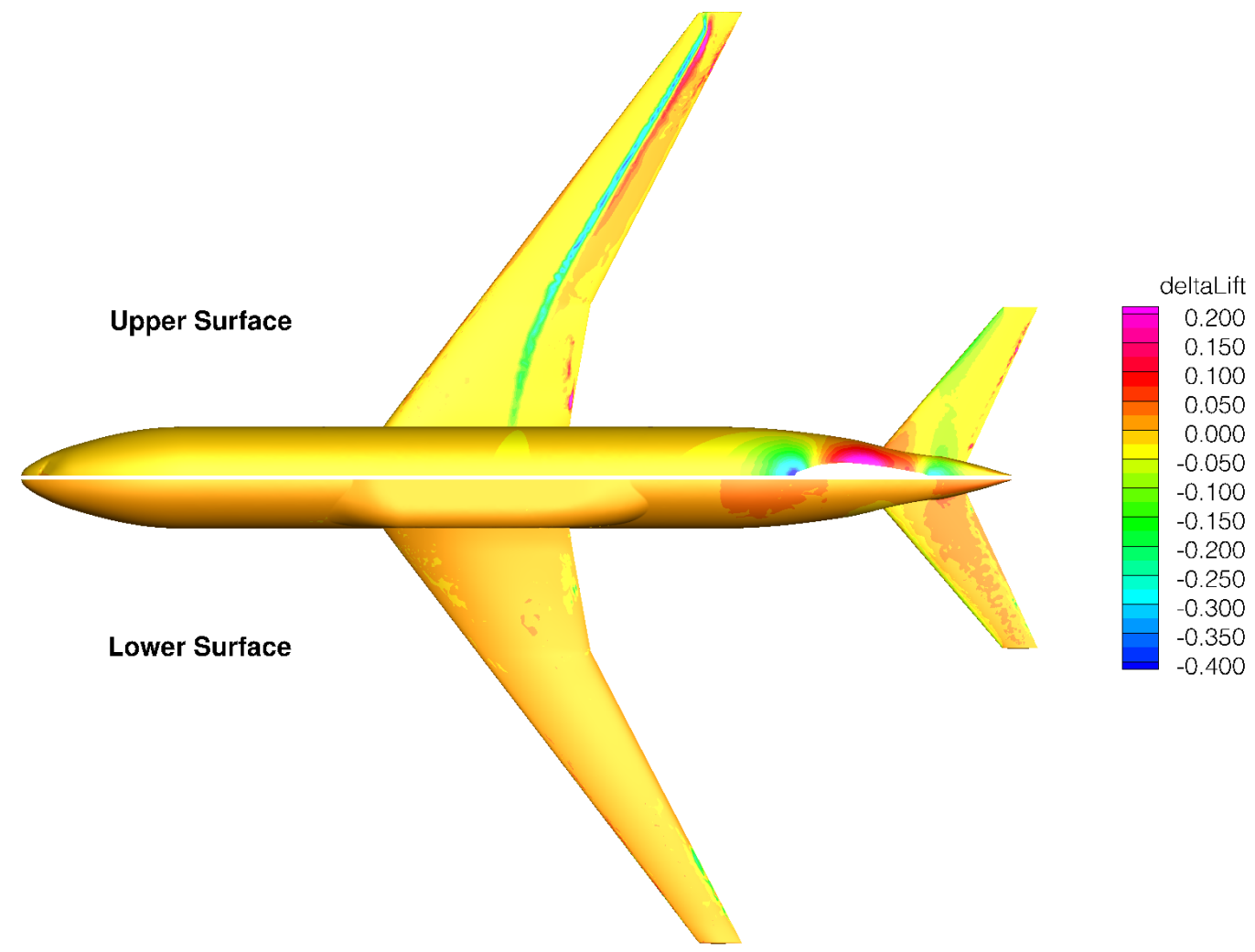

Figure 25. $\delta C_{L}$ contours at $\alpha=2.5^{\circ}$.

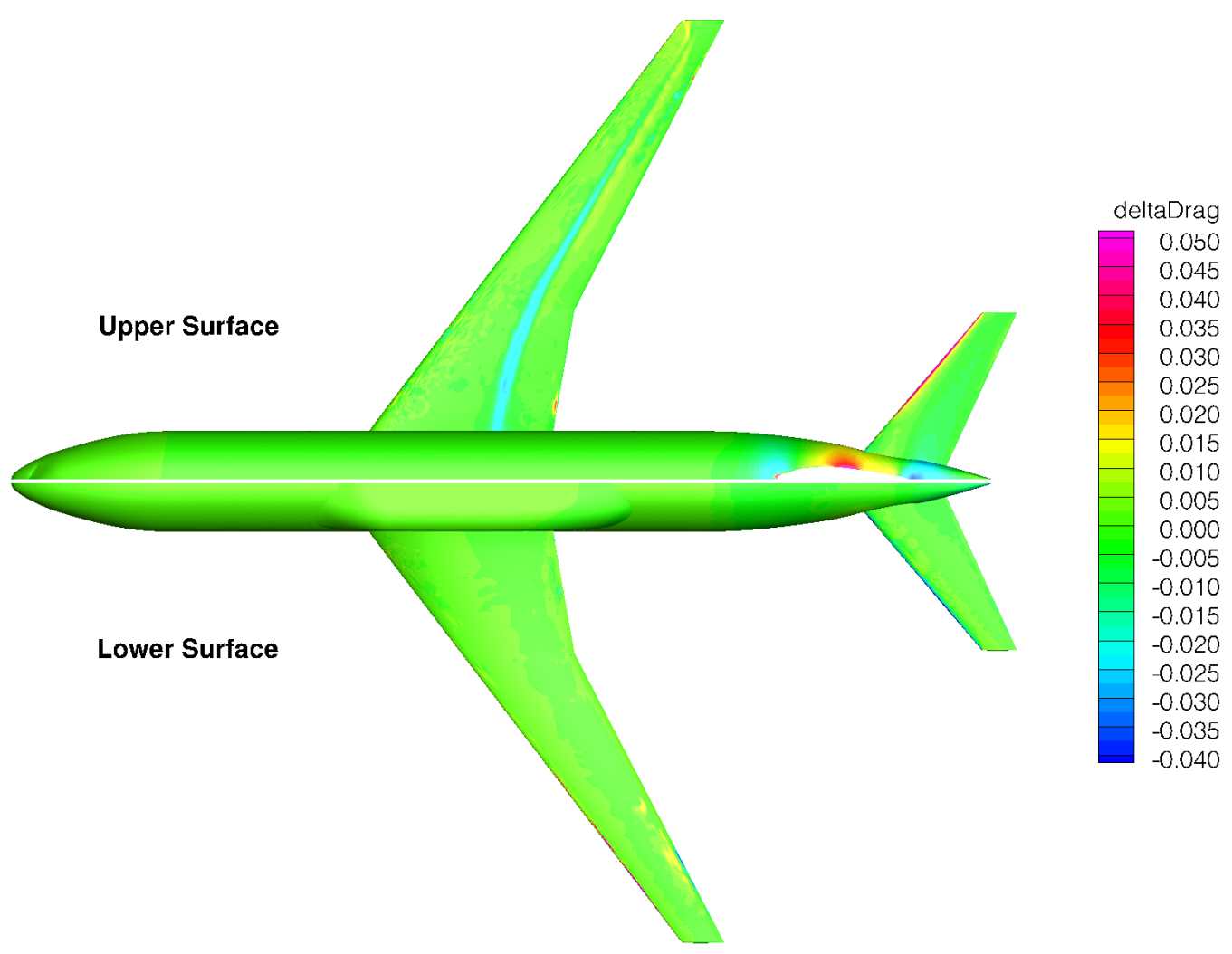

Figure $26 . \delta C_{D}$ contours at $\alpha=2.5^{\circ}$. 


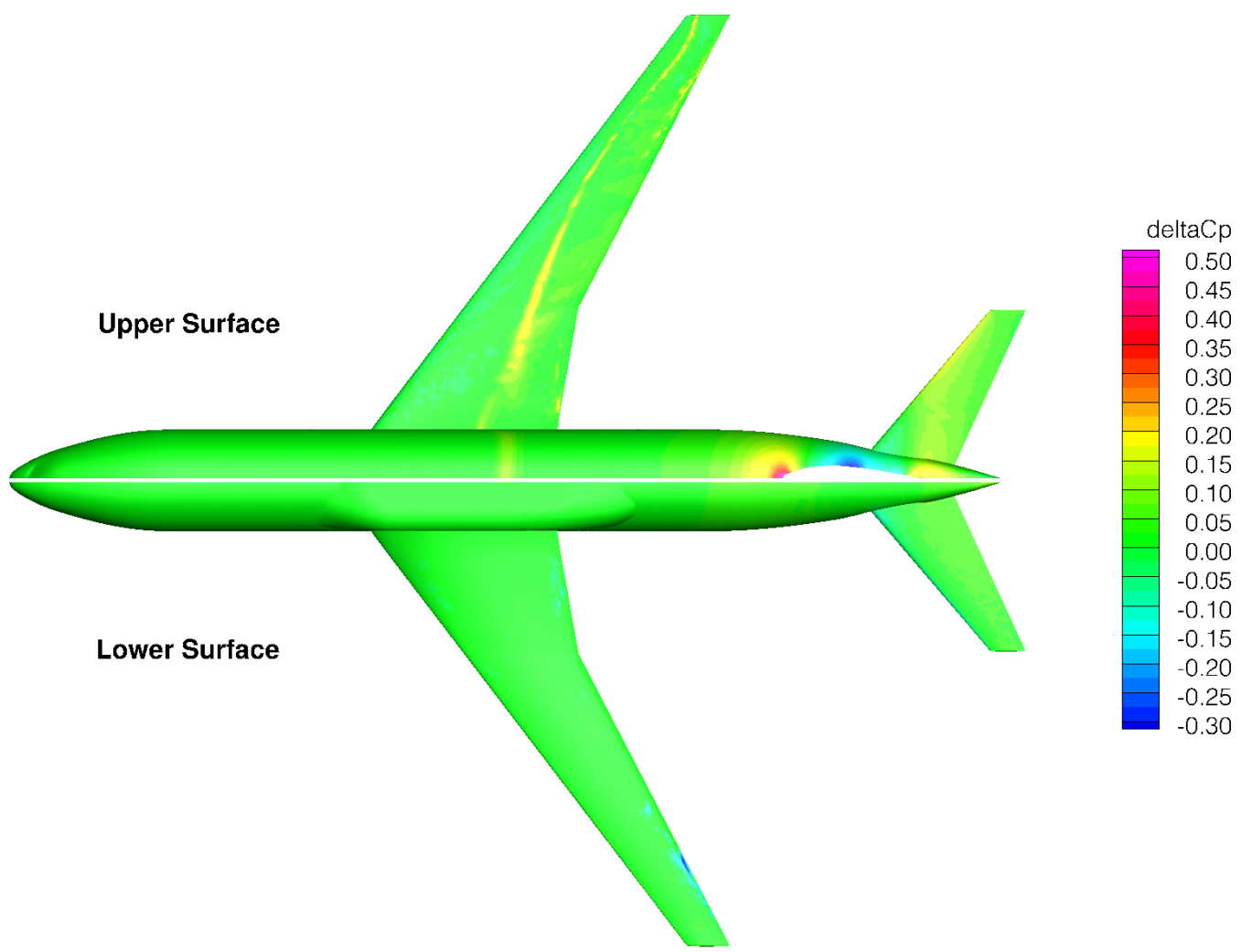

Figure 27. $\Delta C_{P}$ contours at $\alpha=5^{\circ}$.

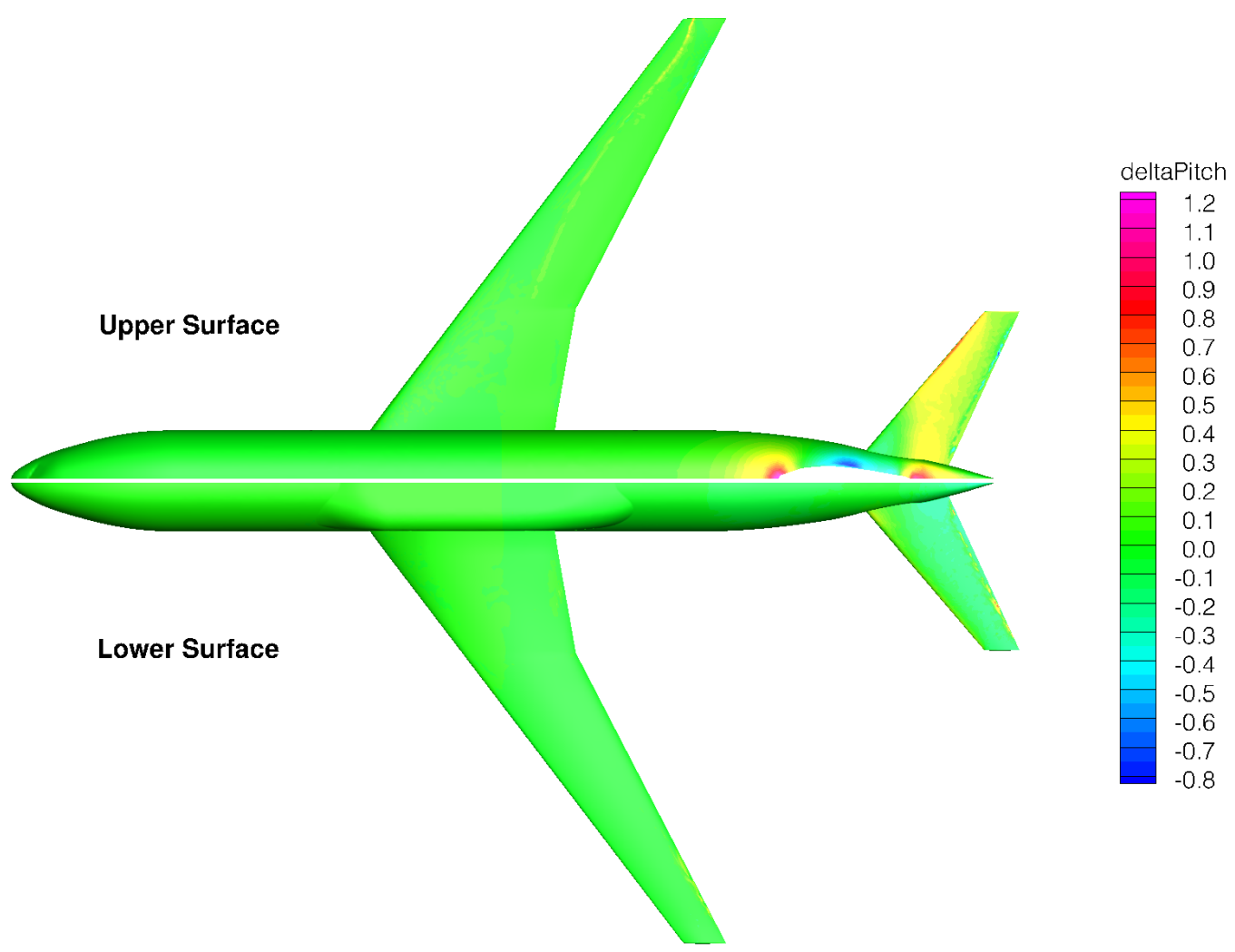

Figure 28. $\delta C_{m}$ contours at $\alpha=5^{\circ}$. 


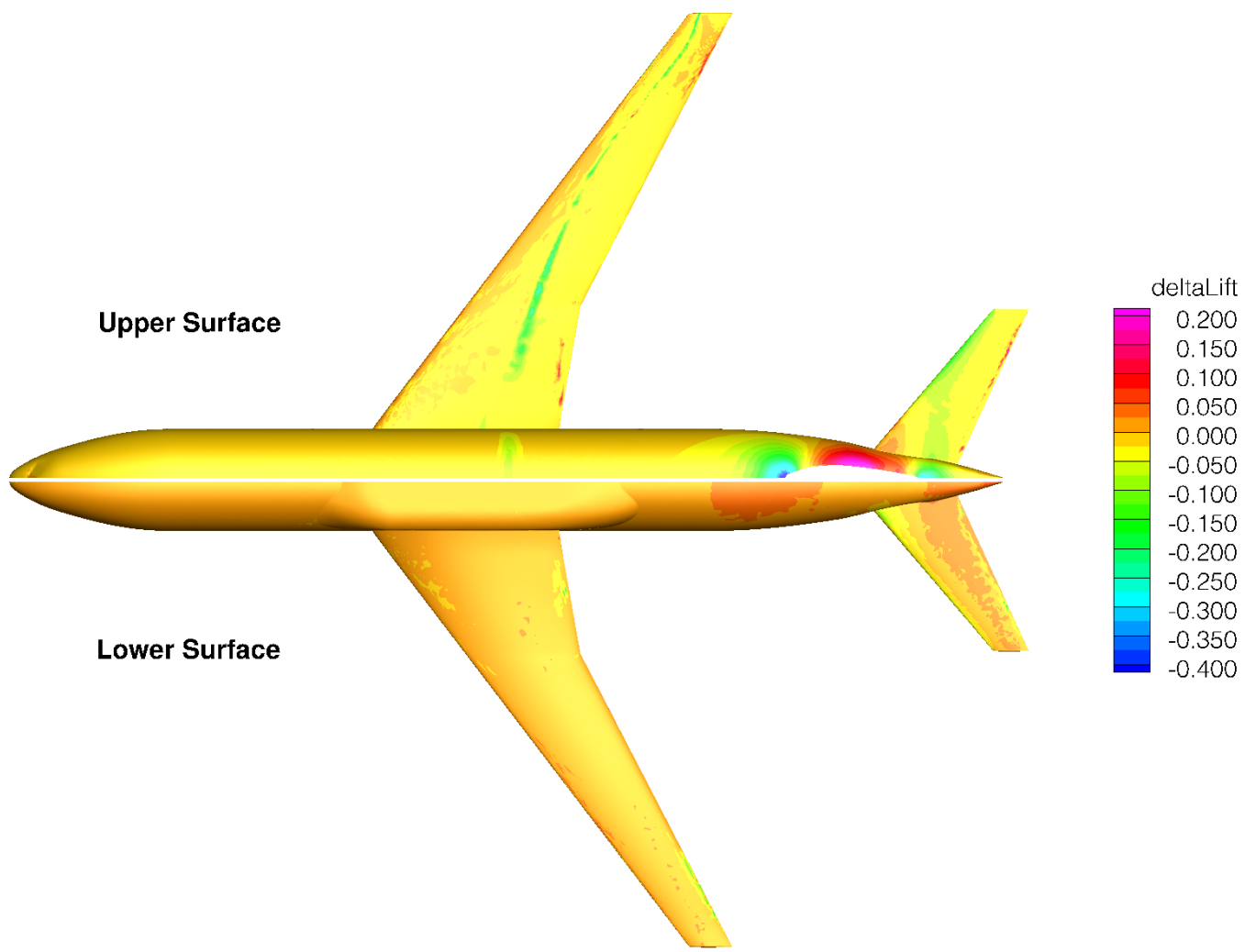

Figure 29. $\delta C_{L}$ contours at $\alpha=5^{\circ}$.

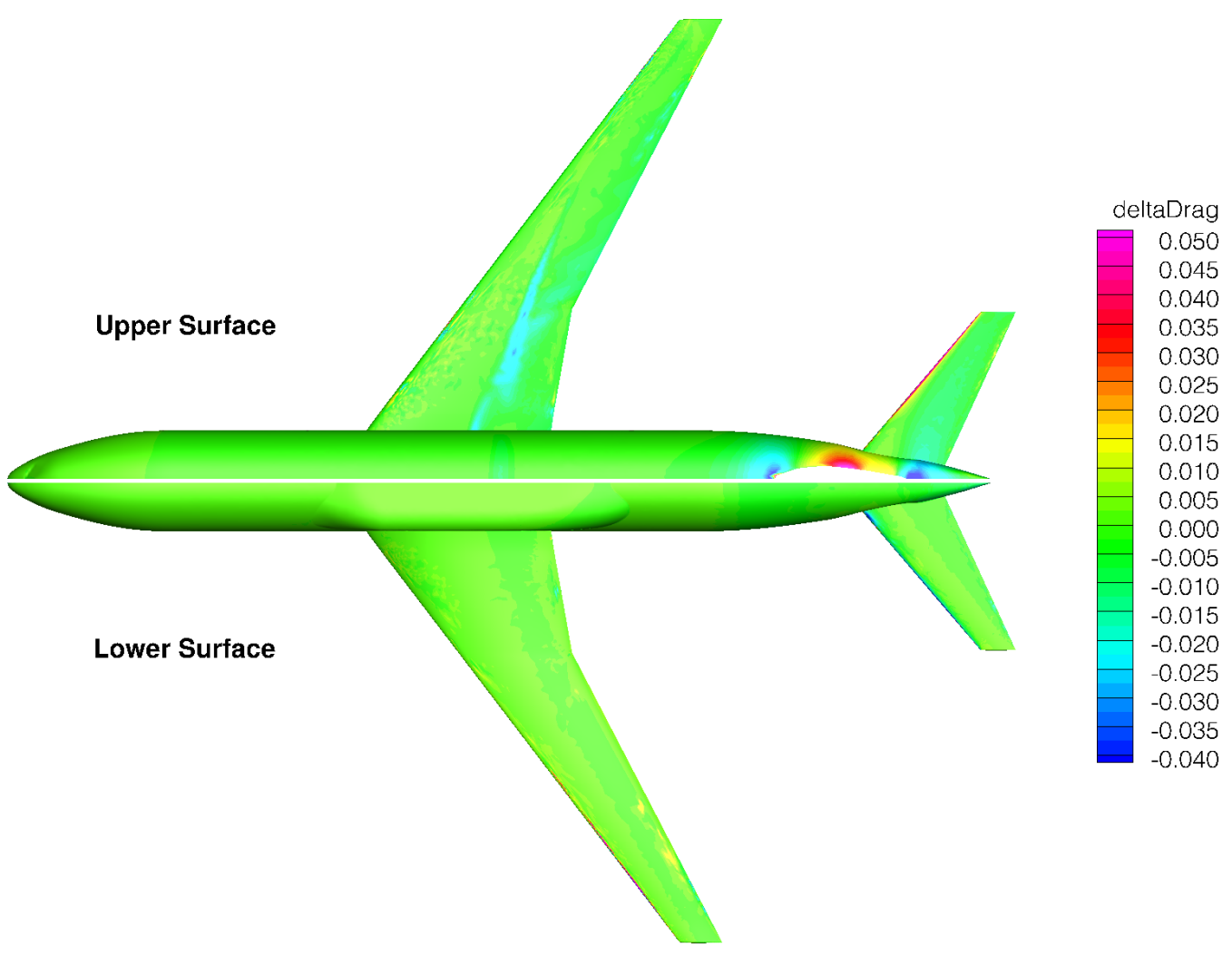

Figure $30 . \delta C_{D}$ contours at $\alpha=5^{\circ}$. 